\title{
Modeling the possible role of iodine oxides in atmospheric new particle formation
}

\author{
S. Pechtl ${ }^{1}$, E. R. Lovejoy ${ }^{2}$, J. B. Burkholder ${ }^{2}$, and R. von Glasow ${ }^{1}$ \\ ${ }^{1}$ Institute for Environmental Physics, University of Heidelberg, Heidelberg, Germany \\ ${ }^{2}$ Aeronomy Laboratory, National Oceanic and Atmospheric Administration, Boulder, CO, USA \\ Received: 9 September 2005 - Published in Atmos. Chem. Phys. Discuss.: 13 October 2005 \\ Revised: 19 December 2005 - Accepted: 16 January 2006 - Published: 20 February 2006
}

\begin{abstract}
We studied the possible role of iodine oxides in atmospheric new particle formation with the one-dimensional marine boundary layer model MISTRA, which includes chemistry in the gas and aerosol phase as well as aerosol microphysics. The chemical reaction set focuses on halogen (Cl-Br-I) chemistry. We included a two-step nucleation parameterization, where in the first step, the "real" nucleation process is parameterized, i.e., the formation of clustersized nuclei via homogeneous condensation of gases. We considered both ternary sulfuric acid-ammonia-water nucleation and homomolecular homogeneous OIO nucleation. For the latter, we derived a parameterization based on combined laboratory-model studies. The second step of the nucleation parameterization treats the "apparent" nucleation rate, i.e., the growth of clusters into the model's lowest size bin by condensable vapors such as OIO. We compared different scenarios for a clean marine versus a polluted continental background atmosphere. In every scenario, we assumed the air to move, independent of its origin, first over a coastal region (where it is exposed to surface fluxes of different reactive iodine precursors) and later over the open ocean. According to these sensitivity studies, in the clean marine background atmosphere OIO can be responsible for both homogeneous nuclei formation and the subsequent growth of the clusters to detectable sizes. In contrast to this, in the continental case with its higher levels of pollutants, gas phase OIO mixing ratios, and hence related nucleation rates, are significantly lower. Compared to ternary $\mathrm{H}_{2} \mathrm{SO}_{4}-\mathrm{NH}_{3}-\mathrm{H}_{2} \mathrm{O}$ nucleation, homogeneous OIO nucleation can be neglected for new particle formation in this case, but OIO can contribute to early particle growth, i.e., to apparent nucleation rates. In general, we found OIO to be more important for the growth of newly
\end{abstract}

Correspondence to: S. Pechtl

(susanne.pechtl@iup.uni-heidelberg.de) formed particles than for the formation of new nuclei. According to our studies, observations of particle "bursts" can only be explained by hot spot-like, not by homogeneously distributed emissions.

\section{Introduction}

Atmospheric aerosols play an important role for the climate of the Earth: They directly interact with solar radiation (e.g. Charlson et al., 1992) and indirectly change cloud characteristics through their role as cloud condensation or ice nuclei (e.g. Lohmann and Feichter, 2005). A prerequisite for the quantification of climate effects related to atmospheric aerosol is a thorough understanding of how new particles form in the atmosphere. Besides direct emissions from sources such as combustion, mechanical production, or sea spray, aerosols can also be produced by in situ nucleation of condensable gases. Several mechanisms are presently regarded as possible contributors to in situ nucleation, such as binary sulfuric acid-water nucleation (Pruppacher and Klett, 1997), ternary sulfuric acid-ammonia-water nucleation (Coffman and Hegg, 1995), or ion-induced nucleation (Turco et al., 1998). Particle bursts observed in coastal regions were proposed to be caused by nucleation of iodine compounds that originate from marine algae fields being exposed during low tide (O’Dowd et al., 2002b; Burkholder et al., 2004; McFiggans et al., 2004). Air samples during field studies as well as algae incubation experiments with different algae species have shown that exposed algae are able to emit a broad spectrum of different kinds of organoiodides such as $\mathrm{CH}_{3} \mathrm{I}, \mathrm{CH}_{2} \mathrm{I}_{2}$, or $\mathrm{CH}_{2} \mathrm{ICl}$ (Carpenter et al., 1999, 2000; Peters et al., 2005). Evidence also exists for emissions of 
molecular iodine by selected algae species (Saiz-Lopez and Plane, 2004; McFiggans et al., 2004; Peters et al., 2005).

The potential of iodine compounds to form new particles has been shown in laboratory studies (Hoffmann et al., 2001; Jimenez et al., 2003; Burkholder et al., 2004), where $\mathrm{CH}_{2} \mathrm{I}_{2}$ or $\mathrm{CF}_{3} \mathrm{I}$ were used as sources for reactive iodine. Hoffmann et al. (2001) suggested that nuclei may form via self-reaction of OIO followed by multiple OIO addition steps leading to the formation of stable iodine oxide clusters. OIO is formed from photodissociation of iodine compounds such as $\mathrm{CH}_{2} \mathrm{I}_{2}$ and $\mathrm{I}_{1}$, producing $\mathrm{I}$ atoms, followed by the rapid reaction with ozone to form IO radicals, which self-react to OIO. However, the exact mechanism of particle formation and its relevance under real atmospheric conditions is still uncertain.

The detection of aerosols has until recently only been possible for particle sizes larger than about $3 \mathrm{~nm}$ in diameter, i.e., the number and composition of freshly formed nuclei (which are about $1 \mathrm{~nm}$ in size) cannot directly be measured. As a consequence, new particles are only detectable if the amount of condensable vapor is large enough to let the nuclei grow with a rate sufficient to limit scavenging by background particles. The species involved in this early growth of clusters do not necessarily have to be the same as those responsible for nucleation: Several studies have indicated that nucleation and the subsequent early growth may be occuring via different vapors, i.e., both processes are likely to be decoupled (Janson et al., 2001; Kulmala et al., 2004b).

The first observations of particle bursts at a clean coastal site (Mace Head, Ireland) were published by O'Dowd et al. (1998), who found correlations of new particle formation with low tide and solar irradiation. In follow-up studies, different possible mechanisms to explain the observed nucleation events were investigated, focusing mainly on the question of whether iodine species homogeneously nucleate to a sufficient extent or whether they are only responsible for the growth of otherwise formed nuclei such as ternary sulfuric acid-ammonia-water clusters (O'Dowd et al., 1999, 2002a,b; McFiggans et al., 2004).

Some modeling studies have been performed focusing on determining the amount of condensable vapor and the nucleation rate required to reproduce the observation at Mace Head (O'Dowd et al., 1999, 2002b; Pirjola et al., 2000, 2002). All studies conclude that sulfuric acid alone cannot account for the observed nucleation bursts, but that further condensable species must be responsible for early particle growth. O'Dowd et al. (2002b) suggested new particle production associated with iodine containing condensable vapors such as $\mathrm{OIO}, \mathrm{I}_{2} \mathrm{O}_{2}$, or HOI. Atmospheric box model calculations by Burkholder et al. (2004) showed that presently published IO and OIO mixing ratios from field observations are not sufficient to account for significant aerosol production, and suggested inhomogeneously distributed sources of iodine oxides, i.e. "hot spots" with elevated reactive iodine precursor emissions as an explanation. Very recently, measurements and model studies by McFiggans et al. (2004) and
Saiz-Lopez et al. (2005) provided strong evidence for molecular iodine to be the most important precursor for new particle formation observed at Mace Head.

The nucleation step itself (driven, as suggested, by homogeneous nucleation of $\mathrm{OIO}$ ) has recently been investigated for the first time by combined laboratory and model studies (Burkholder et al., 2004). So far, no attempt has been made to include new particle formation related to iodine species into a comprehensive model of atmospheric chemistry and microphysics. We developed a parameterization for homogeneous OIO nucleation based on the laboratory and model data of Burkholder et al. (2004), and coupled this together with parameterizations for ternary $\mathrm{H}_{2} \mathrm{SO}_{4}-\mathrm{NH}_{3}-\mathrm{H}_{2} \mathrm{O}$ nucleation and early cluster growth interactively to the one-dimensional marine boundary layer model MISTRA (von Glasow et al., 2002a,b). We especially exploit the nucleation potential of OIO under different environmental conditions, the importance compared to ternary $\mathrm{H}_{2} \mathrm{SO}_{4}-\mathrm{NH}_{3}-\mathrm{H}_{2} \mathrm{O}$ nucleation, and the potential of OIO to contribute to the early growth of freshly nucleated particles. In this paper, we present several idealized scenarios in order to elucidate sensitivities and uncertainties, while in a later paper we will apply our model to observations made during a field campaign at the ICARTT site Appledore Island. In the next section, a detailed model description is provided. An outline of our model scenarios is given in Sect. 3. Results are presented and discussed in Sect. 4. Finally, conclusions are drawn in Sect. 5.

\section{Model description}

We used the one-dimensional marine boundary layer model MISTRA, which includes detailed chemistry in the aqueous (aerosol) phase as well as aerosol microphysics. The model is described in detail in von Glasow et al. (2002a,b). In addition to atmospheric dynamics and thermodynamics, the model includes a detailed microphysical module that calculates particle growth explicitly and accounts for interactions between particles and radiation. A two-dimensional particle size distribution is used, characterized by the total (i.e., the wet) particle radius and the dry aerosol radius the particles would have if they contained no water. The grid is divided into 70 logarithmically equidistant dry aerosol classes with the minimum diameter being $10 \mathrm{~nm}$. Each dry aerosol class is associated with 70 total particle classes. Chemical reactions in the gas phase are treated in all model layers. In the aqueous phase, chemistry is calculated in two aerosol and two droplet classes.

The model includes 198 gas phase reactions (H-O-S-C-N$\mathrm{Cl}-\mathrm{Br}-\mathrm{I})$ that are important for the chemistry of the marine boundary layer, including halogen chemistry. Furthermore, 165 aqueous phase reactions, 18 heterogeneous reactions and 50 equilibria are used for each of the four aqueous phase bins. The iodine reaction scheme, which is of special importance for the present study, is shown in Fig. 1. Several 


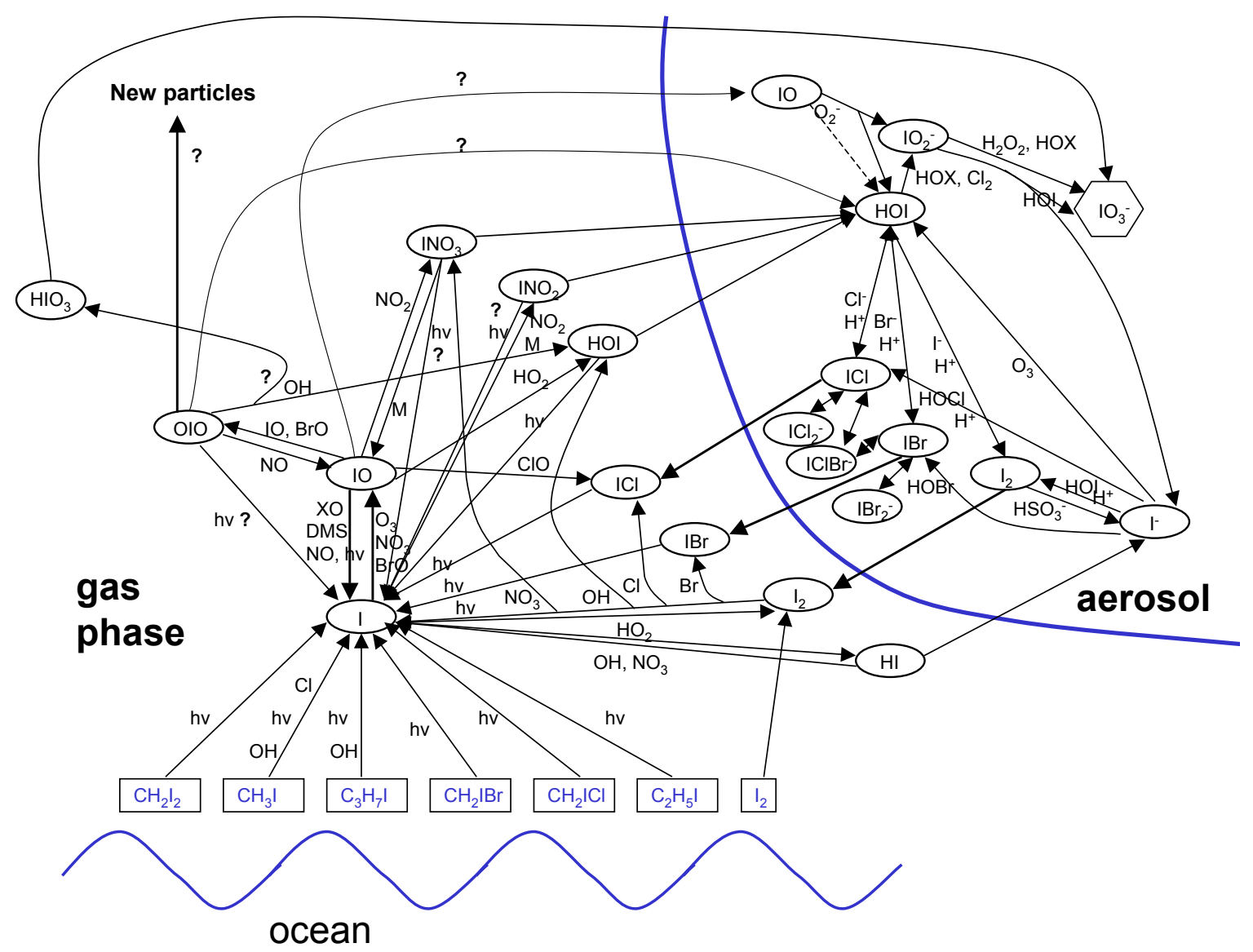

Fig. 1. Scheme of gas and liquid phase iodine chemistry as implemented in MISTRA.

question marks in Fig. 1 denote uncertain reactions in the gas phase. Sensitivity studies, especially with respect to our key species OIO were performed in order to address some of these uncertainties (see Sect. 3). In contrast to earlier studies (Vogt et al., 1999; von Glasow et al., 2002a) we did not include $\mathrm{I}_{2} \mathrm{O}_{2}$ in our reaction scheme since recent thermodynamic calculations indicate that the asymmetric dimer IOIO that forms to up to $60 \%$ from the self-reaction of IO (Atkinson et al., 2004) breaks down in less than a second (Saunders and Plane, 2005). There might also be some contribution of the symmetric dimer IOOI (less than 20\%), which decays quickly to $2 \mathrm{I}+\mathrm{O}_{2}$. Hence, we assume $\mathrm{IO}+\mathrm{IO} \longrightarrow \mathrm{OIO}+\mathrm{I}$ $(>80 \%)$ and $\mathrm{IO}+\mathrm{IO} \longrightarrow 2 \mathrm{I}+\mathrm{O}_{2}(<20 \%)$. Gas phase reactions and respective rate constants involving OIO as used in the present study are provided in Table 1 . The accommodation coefficient for uptake of OIO on aerosol is assumed to be unity. The entire reaction mechanism including the complete set of rate constants and references can be found as electronic attachement to this paper (http://www.atmos-chem-phys.org/ acp/6/505/acp-6-505-sp.pdf).

The nucleation module developed for MISTRA consists of a two-step parameterization: In the first step, the "real" nu- cleation rate of thermodynamic stable clusters is calculated, while in the second step, the growth of these nuclei into the model's lowest particle size bin (diameter $10 \mathrm{~nm}$ ) is computed. As the particles can be included into the model only after the second step of nucleation, we denote the nucleation rate in the model's lowest size bin the "apparent" nucleation rate. Note that this quantity is very useful for field measurements, too, because only an "apparent" nucleation rate of particles exceeding a certain size can be observed.

Regarding the "real" nucleation rate, we implemented two options: (1) homogeneous homomolecular nucleation of $\mathrm{OIO}$, and (2) ternary $\mathrm{H}_{2} \mathrm{SO}_{4}-\mathrm{NH}_{3}-\mathrm{H}_{2} \mathrm{O}$ nucleation relying on the parameterization by Napari et al. (2002). No parameterization has been available so far describing the nucleation of OIO. We developed a parameterization using the approach of Burkholder et al. (2004): They combined laboratory experiments with a coupled chemical - aerosol model, where the experimental results were used to derive necessary model parameters. The nucleation steps of OIO clusters are treated fully kinetically in this model, the model bins increment by single OIO molecules. The temporal evolution of gas phase $\mathrm{OIO}$ and $\mathrm{OIO}$ clusters are described by differential equations 
Table 1. Gas phase reactions involving OIO as used in MISTRA. $n$ is the order of the reaction. The rate coefficients are calculated with $k=A \times \exp \left(\frac{-E_{a}}{R T}\right)$. Reaction rate constants for IO+IO and IO+BrO are taken from Atkinson et al. (2004), for OIO+NO from results of the EU project THALOZ (2005), OIO+OH as assumed by von Glasow et al. (2002a). For photolysis rates only an upper limit of the quantum yield (QY) is available (THALOZ, 2005). Products of OIO photolysis are $\mathrm{I}+\mathrm{O}_{2}$, the channel IO+O is negligible (THALOZ, 2005). If not denoted otherwise $\mathrm{OIO}$ is assumed to be photolytically stable, and $\mathrm{IO}+\mathrm{IO} \longrightarrow \mathrm{OIO}+\mathrm{I}(100 \%)$.

\begin{tabular}{|c|c|c|c|c|c|}
\hline \multicolumn{3}{|c|}{ reaction } & \multirow{2}{*}{$\begin{array}{l}n \\
2\end{array}$} & \multirow{2}{*}{$\begin{array}{l}A\left[\left(\mathrm{~cm}^{-3}\right)^{1-n} \mathrm{~s}^{-1}\right] \\
5.4 \times 10^{-11}\end{array}$} & \multirow{2}{*}{$\frac{-E_{a} / R[\mathrm{~K}]}{180}$} \\
\hline $\mathrm{IO}+\mathrm{IO}$ & $\longrightarrow$ & $\begin{array}{l}\mathrm{OIO}+\mathrm{I}(>80 \%) \\
2 \mathrm{I}+\mathrm{O}_{2}(<20 \%)\end{array}$ & & & \\
\hline $\mathrm{IO}+\mathrm{BrO}$ & $\longrightarrow$ & $\mathrm{Br}+0.8 \mathrm{OIO}+0.2 \mathrm{I}+0.2 \mathrm{O}_{2}$ & 2 & $1.5 \times 10^{-11}$ & 510 \\
\hline $\mathrm{OIO}+\mathrm{OH}$ & $\longrightarrow$ & $0.5 \mathrm{HIO}_{3}+0.5 \mathrm{HOI}$ & 2 & $2.0 \times 10^{-10}$ & \\
\hline $\mathrm{OIO}+\mathrm{NO}$ & $\longrightarrow$ & $\mathrm{NO}_{2}+\mathrm{IO}$ & 2 & $5.1 \times 10^{-13}$ & 712 \\
\hline $\mathrm{OIO}+h v$ & $\longrightarrow$ & $\mathrm{I}+\mathrm{O}_{2}$ & 1 & $\mathrm{QY}<0.1$ & \\
\hline
\end{tabular}

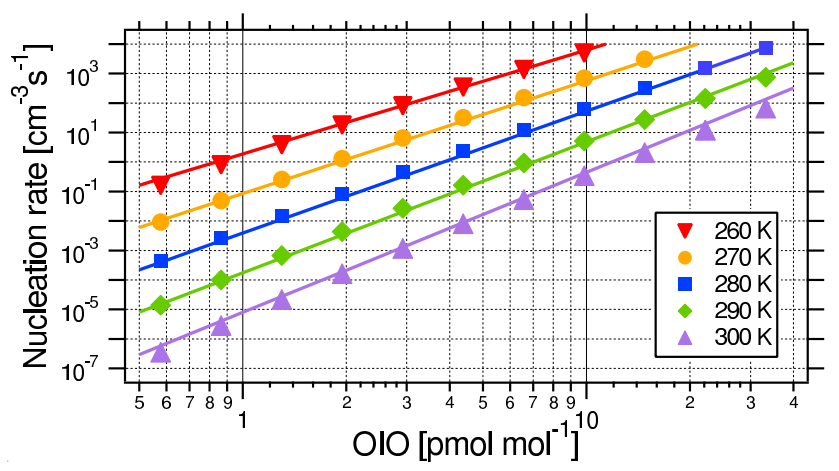

Fig. 2. Nucleation rate of $2 \mathrm{~nm}$ OIO clusters dependent on OIO mixing ratios for different atmospherically relevant temperatures (symbols). Also displayed are empirical fit functions (solid lines, Eq. 1).

(Burkholder et al., 2004, Eqs. 9 and 10). In order to determine nucleation rates, we ran the model of Burkholder et al. (2004) for several combinations of temperature, OIO concentration, and initial background particle surface area, and calculated the production rate of $2 \mathrm{~nm}$ diameter OIO clusters. For a nuclei density of $2 \mathrm{~g} \mathrm{~cm}^{-3}$ the $2 \mathrm{~nm}$ clusters contain 34 OIO molecules. Figure 2 shows the modeled nucleation rate of $2 \mathrm{~nm}$ OIO clusters at steady state (i.e., $\ll 1 \%$ change per integration step) without initial background aerosol surface area, dependent on steady state OIO mixing ratio for different temperatures. Also displayed is the empirical fit function that we derived from the model results as parameterization for homogeneous OIO nucleation:

$J_{\text {real }, \text { OIO }}=\xi_{\text {OIO }}^{0.030657 * T-4.4471} \times e^{-0.30947 * T+81.097}$

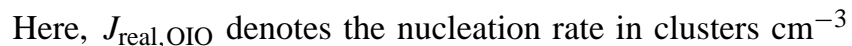
$\mathrm{s}^{-1}, \xi_{\text {OIO }}$ is the OIO mixing ratio in pmol $\mathrm{mol}^{-1}, T$ denotes temperature in $\mathrm{K}$. The parameterization is set up for the range displayed in Fig. 2, i.e., for atmospherically relevant ranges of OIO mixing ratios (up to about $40 \mathrm{pmol} \mathrm{mol}^{-1}$ ) and temperatures $(260-300 \mathrm{~K})$. The nucleation rates provided by the parameterization and by the aerosol model agree at least within a factor of two, for most values the agreement is much better (see Fig. 2). The omission of initial background aerosol is justified as we found that the $2 \mathrm{~nm}$ particle production rate is fairly insensitive to initial background particle surface area $\left(0-140 \mu \mathrm{m}^{2} \mathrm{~cm}^{-3}\right)$ because loss to background aerosol is small compared to the cluster growth, especially for large OIO mixing ratios, i.e. high, atmospherically relevant nucleation rates. Nucleation rates for initial surface areas of $0 \mu \mathrm{m}^{2} \mathrm{~cm}^{-3}$ versus $140 \mu \mathrm{m}^{2} \mathrm{~cm}^{-3}$ agree at least within a factor of 1.2 for nucleation rates down to 100 nuclei $\mathrm{cm}^{-3} \mathrm{~s}^{-1}$, and still within a factor of 1.5 for small nucleation rates around 1 nucleus $\mathrm{cm}^{-3} \mathrm{~s}^{-1}$. In the aerosol model simulations, particle surface area is not restricted, i.e., although we start with no background particle surface area, surface area increases as new particles form. As for very high particle nucleation rates, the strong increase in surface area prevents a steady state, we restrict the validity of our parameterization to nucleation rates $<10^{4}$ nuclei $\mathrm{cm}^{-3} \mathrm{~s}^{-1}$.

Besides homogeneous $\mathrm{OIO}$ nucleation, ternary $\mathrm{H}_{2} \mathrm{SO}_{4}$ $\mathrm{NH}_{3}-\mathrm{H}_{2} \mathrm{O}$ nucleation combined with further nuclei growth through iodine compounds is the most likely candidate for explaining coastal nucleation bursts (O'Dowd et al., 1999, $2002 b)$. Therefore, the second "real" nucleation process we include in our model is ternary $\mathrm{H}_{2} \mathrm{SO}_{4}-\mathrm{NH}_{3}-\mathrm{H}_{2} \mathrm{O}$ nucleation. Here, we rely on a parameterization deduced by Napari et al. (2002) from results of a self-consistent model of ternary nucleation. Ternary nucleation rates are calculated as a function of $\mathrm{H}_{2} \mathrm{SO}_{4}$ and $\mathrm{NH}_{3}$ concentrations, temperature, and relative humidity, the nuclei diameter is set up as a function of temperature and nucleation rate. The parameterization is valid for temperatures $240-300 \mathrm{~K}$, relative humidities $5-95 \%$, sulfuric acid concentrations $10^{4}-10^{9}$ molec $\mathrm{cm}^{-3}$, ammonia mixing ratios $0.1-100 \mathrm{pmol} \mathrm{mol}^{-1}$ and nucleation rates $10^{-5}-10^{6}$ nuclei $\mathrm{cm}^{-3} \mathrm{~s}^{-1}$. Figure 3 shows ternary nucleation rates for a fixed temperature $(290 \mathrm{~K})$ and relative humidity $(63 \%)$ dependent on $\mathrm{H}_{2} \mathrm{SO}_{4}$ and $\mathrm{NH}_{3}$ concentrations, 
where temperature and humidity are chosen such that they are representative for the MISTRA sensitivity studies presented below. Note, however, that the ternary nucleation rates are still considerably uncertain as the classical nucleation model itself has not been validated by experiments due to the lack of suitable experimental data (Napari et al., 2002).

The "apparent" nucleation rate, i.e., the early growth of the freshly formed clusters into the model's lowest size bin, is calculated from the "real" nucleation rate by means of a parameterization by Kerminen and Kulmala (2002), using information about the "real" and "apparent" particle diameters, as well as parameterized growth and sink processes: The nuclei grow by condensation of non-volatile vapors. Gas phase diffusion and the transitional correction for the condensational mass flux (Fuchs and Sutugin, 1970) are implicitly accounted for. It is assumed that the particles are in equilibrium with ambient humidity, i.e., water vapor enhances the particle growth rate. Sink processes are condensation of the condensable vapors onto background particles, as well as coagulation of the nuclei with background particles. Selfcoagulation among nuclei is not accounted for in the parameterization, i.e., total nuclei numbers must remain sufficiently low to prevent efficient self-coagulation $\left(<10^{6}\right.$ nuclei $\left.\mathrm{cm}^{-3}\right)$.

In oder to be able to include not only strictly non-volatile, but also low-volatile vapors into particle growth, we extended the parameterization according to Kerminen et al. (2004) by introducing a critical diameter (between the "real" and the "apparent" particle size): For cluster sizes below the critical diameter, the nuclei grow only by non-volatile vapors, while they grow additionally by (supersaturated) lowvolatile vapors (i.e., with a larger total growth rate) for cluster sizes above the critical diameter. The critical particle size is calculated as a function of the actual supersaturation of the respective low-volatile vapor (Kerminen et al., 2004, Eq. 10). This extension for low-volatile vapors was developed mainly in order to include organic vapors that, according to recent theoretical arguments (Anttila et al., 2004; Kulmala et al., 2004a) can "activate" aqueous inorganic nuclei after reaching a sufficiently large size. However, it is equally suitable for other supersaturated vapors with a non-zero saturation vapor pressures.

Nucleation interacts with the model's background aerosol distribution: Nucleation enhances background particle number densities, which feeds back on nucleation by enhancing the sink processes for nucleation. Vapor that is condensing onto nuclei is removed from the gas phase and added to the aqueous phase. OIO as the condensable vapor of main interest in this study is assumed to be non-reactive in the aqueous phase due to lack of knowledge regarding further possible liquid phase reactions. Nucleation therefore occurs as a net sink for gas phase OIO. Besides OIO, any other condensable vapor(s) can be chosen as contributors to early cluster growth. Hence, the nucleation parameterization as used in this study can be flexibly used for different environmental conditions.

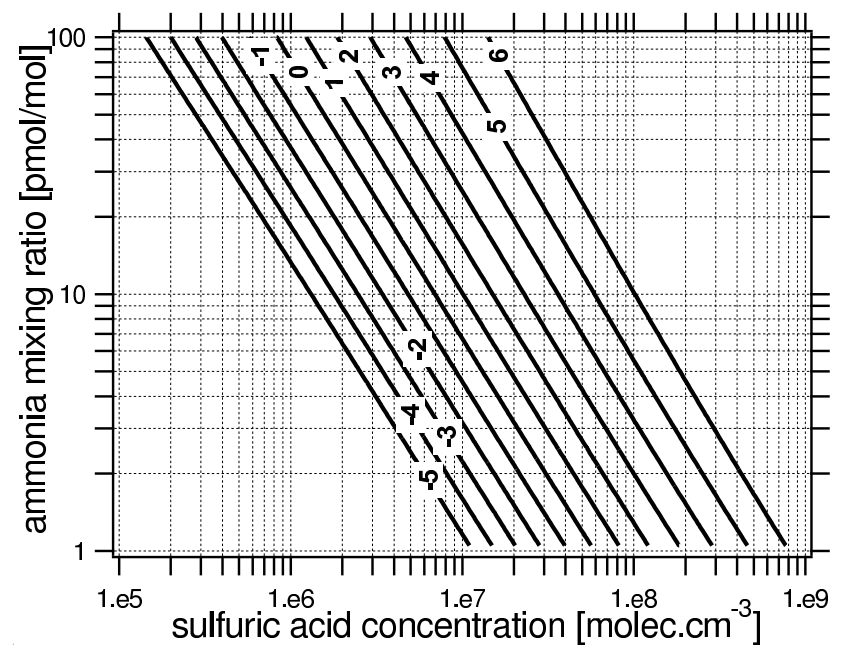

Fig. 3. Ternary $\mathrm{H}_{2} \mathrm{SO}_{4}-\mathrm{NH}_{3}-\mathrm{H}_{2} \mathrm{O}$ nucleation rates (isolines labeled with the logarithm of the nucleation rate in nuclei $\mathrm{cm}^{-3} \mathrm{~s}^{-1}$ ) dependent on sulfuric acid concentration and ammonia mixing ratio for fixed temperature $(290 \mathrm{~K})$ and fixed relative humidity $(63 \%)$ as being representative for our sensitivity studies.

\section{Model setup and sensitivity studies}

We compare new particle formation at coastal sites regarding two different idealized air masses: a clean marine air mass versus a polluted continental air mass as being typical for the outflow from the North American continent towards the Atlantic ocean. In either case, the meteorology resembles conditions encountered during the summer 2004 ICARTT field campaign at Appledore Island, which is located about $10 \mathrm{~km}$ off the New England coast. The latitude is $43^{\circ} \mathrm{N}$ with a solar declination of $20^{\circ}$ (end of July). We chose the initial conditions such that no clouds form and that the boundary layer height is about $700 \mathrm{~m}$, where moisture and heat fluxes from the surface are adjusted to yield a constant boundary layer height. The near-surface temperature is about $16^{\circ} \mathrm{C}$, the humidity increases from about $65 \%$ near the surface to about $90 \%$ near the boundary layer top.

The concept of our scenarios is illustrated in Fig. 4: After spin-up of the meteorological part of the model for 2 days, the complete model is run for (at least) one day in order to condition chemistry to either clean or polluted ambient air. In the clean marine case, we use similar initial concentrations as in von Glasow et al. (2002a) for their sensitivity studies for the remote marine boundary layer. We assume open ocean fluxes of DMS $\left(1 \times 10^{9}\right.$ molec $\left.\mathrm{cm}^{-2} \mathrm{~s}^{-1}\right)$, and, regarding iodine precursers, of $\mathrm{I}_{2}\left(2 \times 10^{6}\right.$ molec $\mathrm{cm}^{-2} \mathrm{~s}^{-1}$ after Garland and Curtis, 1981) and $\mathrm{CH}_{3} \mathrm{I}\left(6 \times 10^{6}\right.$ molec $\left.\mathrm{cm}^{-2} \mathrm{~s}^{-1}\right)$. The latter flux, which is adjusted to yield a steady-state $\mathrm{CH}_{3} \mathrm{I}$ mixing ratio of about $2 \mathrm{pmol} \mathrm{mol}^{-1}$, is about $1 / 3$ of the value Richter and Wallace (2004) found as average flux during a ship cruise in the tropical Atlantic. We assume a typical marine background aerosol size distribution (Hoppel and Frick, 


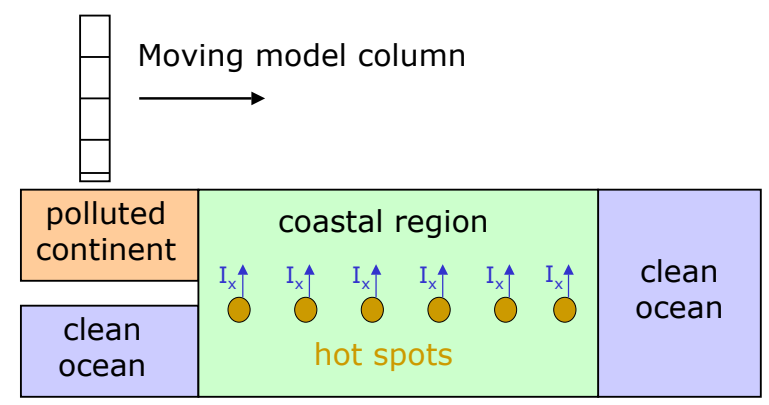

Fig. 4. Sketch of the scenarios: The model column is conditioned for about one day over the different regions (clean marine vs. polluted continental atmospheres) and then moves over coastal regions with emissions of iodine compounds and later over the ocean.

Table 2. Approximate mixing ratios (in $\mathrm{nmol} \mathrm{mol}^{-1}$ ) for the clean marine and polluted continental case at $15 \mathrm{~m}$ altitude at the beginning of the sensitivity studies that start at local noon.

\begin{tabular}{lcc}
\hline species & clean & polluted \\
\hline $\mathrm{NO}_{2}$ & 0.007 & 2.0 \\
$\mathrm{O}_{3}$ & 19 & 50 \\
$\mathrm{NH}_{3}$ & 0.06 & 0.11 \\
$\mathrm{SO}_{2}$ & 0.05 & 0.95 \\
$\mathrm{CO}$ & 65 & 160 \\
$\mathrm{CH}_{4}$ & 1800 & 1800 \\
alkanes & 0.46 & 2.3 \\
alkenes & - & 0.29 \\
aromatics & - & 0.23 \\
$\mathrm{HCHO}$ & 0.15 & 0.75 \\
$\mathrm{HCl}$ & 0.03 & 0.25 \\
$\mathrm{CH}_{3} \mathrm{I}$ & 0.002 & - \\
$\mathrm{I}_{2}$ & 0.00005 & - \\
\hline
\end{tabular}

1990) with an initial surface area of $70 \mu \mathrm{m}^{2} \mathrm{~cm}^{-3}$. It is distinguished between the "sulfate" aerosol (dry aerosol radius $<0.5 \mu \mathrm{m}$; initial composition $32 \%\left(\mathrm{NH}_{4}\right)_{2} \mathrm{SO}_{4}, 65.6 \%$ $\mathrm{NH}_{4} \mathrm{HSO}_{4}, 0.4 \% \mathrm{NH}_{4} \mathrm{NO}_{3}$ ) and the "sea salt" aerosol (dry radius $>0.5 \mu \mathrm{m}$; initial composition like sea water). The emisson of sea salt aerosol via bursting bubbles at the sea surface is calculated using the parameterization of Monahan et al. (1986). For the polluted continental case we assume conditioning of chemistry over the continent, where emissions are adjusted in a way that the resulting mixing ratios resemble roughly those measured during the ICARTT campaign. We use a typical rural aerosol size distribution (Jaenicke, 1988) with an initial surface area of $170 \mu \mathrm{m}^{2}$ $\mathrm{cm}^{-3}$, and presume emissions of neither sea salt nor DMS or any bromine or iodine compounds.

After conditioning of meteorology and chemistry, we run different scenarios, each extending over 5 model hours. During the first $3 \mathrm{~h}$ air masses are assumed to move over a coastal region, where algae fields are exposed during low tide, during the last $2 \mathrm{~h}$ clean open ocean conditions are assumed to allow for studying the temporal evolution upon completion of the exposure to coastal iodine fluxes. The mixing ratios of the most important compounds at the beginning of (most of) the sensitivity studies (at local noon) are listed in Table 2 for both the clean marine and the polluted continental cases. Except for the initial mixing ratios, all scenarios are performed under identical conditions, implying that the air masses move over the same marine coastal regions, independent of their origin. That is, boundary conditions regarding emissions of chemical compounds and sea salt aerosols are always adapted from the marine run. All scenarios and their characteristic differences are listed in Table 3, which will be explained in detail in Sect. 4. While in the continuous emission scenarios the emissions are assumed to occur continuously during the first 3 model hours, in the "hot spot" cases we assume pulse emissions every half hour, each pulse lasting for $5 \mathrm{~min}$. Considering a moving model column, these "temporal" processes can also be interpreted as (homogeneous or inhomogeneous) "spatial" distributions. The emission fluxes are chosen such that the time-integral, i.e., the absolute amount of emissions, is the same for the continuous and the "hot spot" emission cases. The scenarios are compared to a base case scenario (scenario 0), where we assume clean marine conditions for the whole 5 model hours.

The design of our sensitivity studies allows us to address the following questions: In which air masses can homogeneous nucleation of OIO be important compared to ternary $\mathrm{H}_{2} \mathrm{SO}_{4}-\mathrm{NH}_{3}-\mathrm{H}_{2} \mathrm{O}$ nucleation? Is OIO equally important for homogeneous nuclei formation and for the early cluster growth? Do the model simulation support the theory that reactive iodine precursors are emitted in localized "hot spots" rather than continuously over a large area? How far from the source and up to which altitude can nucleation events be detected? What is the potential role of molecular iodine? How sensitive are the results to different times of the day? How can sulfuric acid or potentially other low-volatile iodine compounds affect early particle growth? How sensitive are the results towards uncertainties in iodine chemistry?

\section{Results and discussion}

The results of the sensitivity studies listed in Table 3 are presented and discussed in the following subsections. First, we discuss in detail the conditions in a clean marine background air mass, comparing alkyl iodide emissions occuring continuously with those in hot spots. In Sect. 4.2, we compare differences between clean marine and polluted continental air masses with respect to properties important for iodine oxide nucleation. Subsequently, we discuss effects of the diurnal cycle as well as sensitivities towards uncertainties in iodine chemistry. 
Table 3. Scenarios and their characteristics used in this paper. All scenarios extend over 5 model hours, where the air mass is assumed to move over a coastal region during the first $3 \mathrm{~h}$. Unless denoted otherwise, scenarios start at local noon, nuclei form by both OIO nucleation and ternary $\mathrm{H}_{2} \mathrm{SO}_{4}-\mathrm{NH}_{3}-\mathrm{H}_{2} \mathrm{O}$ nucleation and grow by $\mathrm{OIO}$ only.

\begin{tabular}{|c|c|c|}
\hline No. & air mass & characteristics \\
\hline 0 & marine & base case without emissions of iodine species \\
\hline 0 & continental & base case without emissions of iodine species \\
\hline 1 & marine & continuous emissions of alkyl iodides \\
\hline 1 & continental & continuous emissions of alkyl iodides \\
\hline 2 & marine & hot spot emissions of alkyl iodides \\
\hline 2 & continental & hot spot emissions of alkyl iodides \\
\hline 3 & marine & hot spot emissions of alkyl iodides and $\mathrm{I}_{2}$ \\
\hline 3 & continental & hot spot emissions of alkyl iodides and $\mathrm{I}_{2}$ \\
\hline 4 & marine & as 3 , but scenario starts at 04:00 \\
\hline 4 & continental & as 3 , but scenario starts at $04: 00$ \\
\hline 5 & marine & as 3 , but scenario starts at $18: 00$ \\
\hline 5 & continental & as 3 , but scenario starts at $18: 00$ \\
\hline 6 & continental & as 3 , but particles grow by $\mathrm{OIO}$ and $\mathrm{H}_{2} \mathrm{SO}_{4}$ \\
\hline 7 & marine & as 3 , but particles grow by $\mathrm{OIO}$ and $\mathrm{HOI}$ \\
\hline 8 & marine & as 3 , but excluding the reaction $\mathrm{OIO}+\mathrm{OH}$ \\
\hline 9 & marine & as 3 , but including OIO photolysis (max. photolysis frequency $0.48 \mathrm{~s}^{-1}$ ) \\
\hline 9 & continental & as 3 , but including OIO photolysis (max. photolysis frequency $0.48 \mathrm{~s}^{-1}$ ) \\
\hline 10 & marine & as 3 , but including OIO photolysis (max. photolysis frequency $0.02 \mathrm{~s}^{-1}$ ) \\
\hline 11 & marine & as 3 , but $\mathrm{IO}+\mathrm{IO} \longrightarrow 0.8 \mathrm{OIO}+1.2 \mathrm{I}+0.2 \mathrm{O}_{2}$ \\
\hline 12 & continental & as 3 , but lower limit of reaction rate constant $\mathrm{OIO}+\mathrm{NO}$ used \\
\hline 13 & continental & as 3 , but upper limit of reaction rate constant $\mathrm{OIO}+\mathrm{NO}$ used \\
\hline 14 & marine & as 3 , but including $\mathrm{I}_{2} \mathrm{O}_{3}$ and $\mathrm{I}_{2} \mathrm{O}_{4}$ \\
\hline 14 & continental & as 3 , but including $\mathrm{I}_{2} \mathrm{O}_{3}$ and $\mathrm{I}_{2} \mathrm{O}_{4}$ \\
\hline
\end{tabular}

4.1 Clean marine case: hot spots versus continuous emissions

In order to determine nucleation potentials for continous emissions versus hot spot emissions of reactive iodine precursors, we compare scenarios 1 to 3 for a clean marine background atmosphere (Table 3). Surface emission fluxes of alkyl iodides, representing emissions from exposed coastal algae, are adjusted in a way that the resulting mixing ratios are in accordance with available observations (Table 4). As during the ICARTT Appledore Island campaign $\mathrm{CH}_{3} \mathrm{I}$, $\mathrm{CH}_{2} \mathrm{H}_{5} \mathrm{I}$, and $\mathrm{CH}_{2} \mathrm{ClI}$ were monitored (and detected at mixing ratios up to $3.2,0.3$, and $4.9 \mathrm{pmol} \mathrm{mol}^{-1}$, B. Sive, pers. comm.), but not $\mathrm{CH}_{2} \mathrm{I}_{2}$ or $\mathrm{CH}_{2} \mathrm{BrI}$, we also use results from earlier in situ measurements which showed that the emission pattern of exposed algae normally consists of several different alkyl iodine compounds (for a compilation of respective measurements see Table 4 of Peters et al., 2005).

Except for organoiodides, molecular iodine has been discussed as precursor for iodine oxides and, hence, new particle formation, since it was recently detected in Mace Head at mixing ratios of up to $90 \mathrm{pmol} \mathrm{mol}^{-1}$ at night (Saiz-Lopez and Plane, 2004; McFiggans et al., 2004; Saiz-Lopez et al., 2005). Peters et al. (2005) found that high $\mathrm{I}_{2}$ mixing ratios of up to $60 \mathrm{pmol} \mathrm{mol}^{-1}$ were only present during episodes of unusually low tide and suggested that the release of molecular iodine was a special feature of macroalgae living only in the lower intertidal and sublittoral fringe. Furthermore, high $\mathrm{I}_{2}$ mixing ratios appear in the measurements as sharp peaks, i.e., fluxes of molecular iodine are likely to be large enough to establish a high concentration in quite a short time period of less than one hour. We used this information to estimate the surface emission flux of $\mathrm{I}_{2}$, adjusting it in a way that an $\mathrm{I}_{2}$ mixing ratio of $30 \mathrm{pmol} \mathrm{mol}^{-1}$ was achieved at night at $15 \mathrm{~m}$ altitude after $20 \mathrm{~min}$ constant flux emissions into the same air mass.

Figures 5 and 6 show the 5-h timeseries for important gas phase species and nucleation properties, respectively, of scenarios $1-3$ at $15 \mathrm{~m}$ altitude. In the continuous emission case (red lines) mixing ratios of alkyl iodides range always below $4 \mathrm{pmol} \mathrm{mol}^{-1}$. Of all organoiodides $\mathrm{CH}_{2} \mathrm{I}_{2}$ is the most important precursor for I radicals as its photolytic lifetime of some minutes is an order of magnitude shorter than the next short-lived alkyl iodide $\mathrm{CH}_{2} \mathrm{BrI}$. In the continuous emission runs, IO barely exceeds $3 \mathrm{pmol} \mathrm{mol}^{-1}$ after $3 \mathrm{~h}$, whereas OIO reaches up to $17 \mathrm{pmol} \mathrm{mol}^{-1}$. While the modeled IO mixing ratios are in accordance with available measurements (compare Table 1 of Peters et al., 2005), OIO exceeds DOAS (differential optical absorption spectroscopy) 

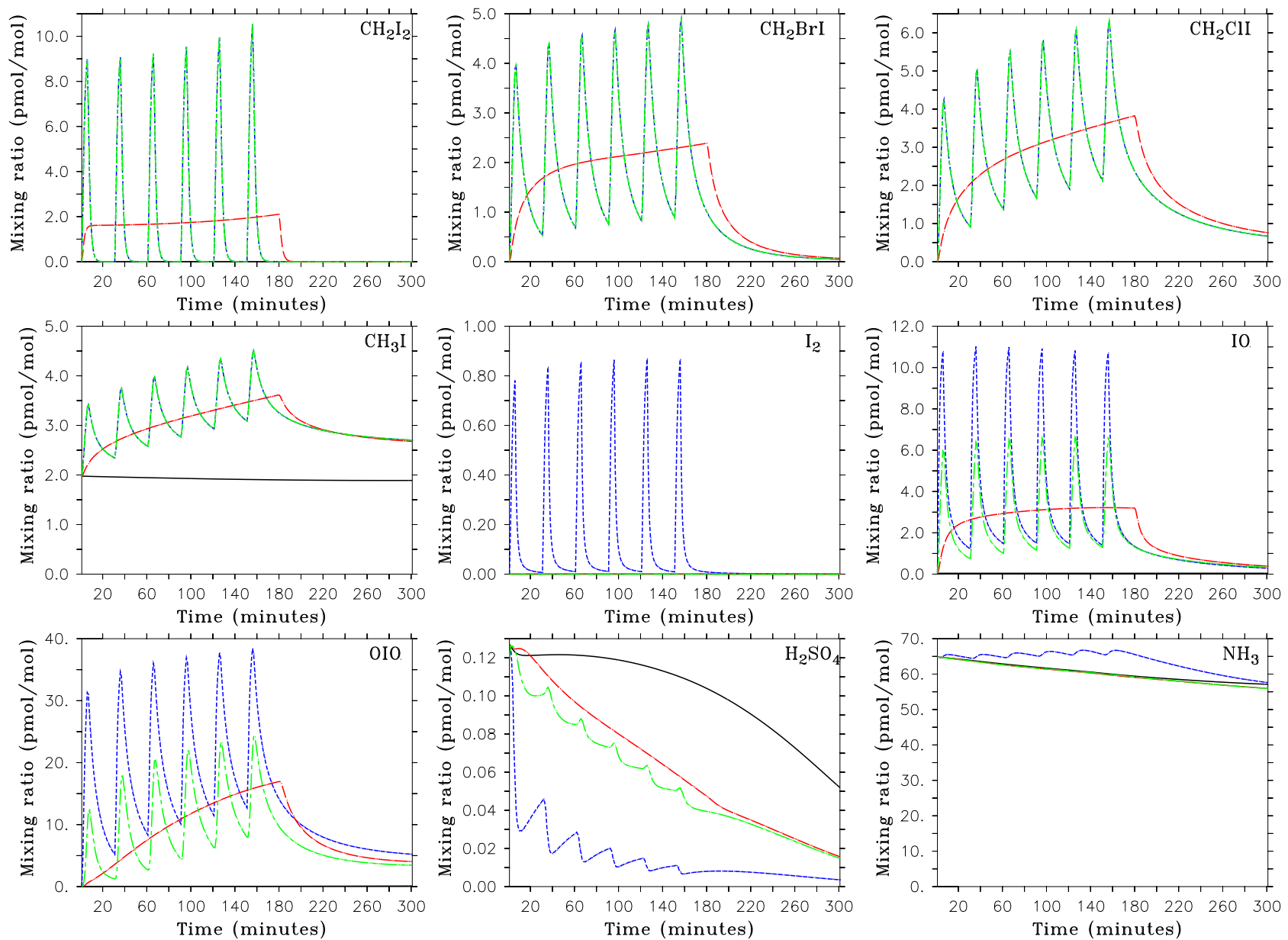

Fig. 5. 5-h timeseries of mixing ratios of important gas phase species at $15 \mathrm{~m}$ altitude for different scenarios for the marine case: scenario 0 (black - solid), scenario 1 (red - dashed), scenario 2 (green - dash-dotted), scenario 3 (blue - dotted). All model runs start at local noon. Note that in the first four plots the blue and the green curves are identical.

Table 4. Surface emission fluxes of alkyl iodides and molecular iodine as prescribed in the different scenarios.

\begin{tabular}{llll}
\hline scenarios & emission type & species & flux $\left[\mathrm{cm}^{-2} \mathrm{~s}^{-1}\right]$ \\
\hline 1 & continuous & $\mathrm{CH}_{3} \mathrm{I}$ & $1.0 \times 10^{8}$ \\
1 & continuous & $\mathrm{CH}_{2} \mathrm{CII}$ & $3.0 \times 10^{8}$ \\
1 & continuous & $\mathrm{CH}_{2} \mathrm{BrI}$ & $3.0 \times 10^{8}$ \\
1 & continuous & $\mathrm{CH}_{2} \mathrm{I}_{2}$ & $2.0 \times 10^{9}$ \\
\hline 2,3 & hot spot & $\mathrm{CH}_{3} \mathrm{I}$ & $6.0 \times 10^{8}$ \\
2,3 & hot spot & $\mathrm{CH}_{2} \mathrm{ClI}$ & $1.8 \times 10^{9}$ \\
2,3 & hot spot & $\mathrm{CH}_{2} \mathrm{BrI}$ & $1.8 \times 10^{9}$ \\
2,3 & hot spot & $\mathrm{CH}_{2} \mathrm{I}_{2}$ & $1.2 \times 10^{10}$ \\
3 & hot spot & $\mathrm{I}_{2}$ & $3.0 \times 10^{10}$ \\
\hline
\end{tabular}

observations by Allan et al. (2001) and Saiz-Lopez and Plane (2004), who detected OIO only up to about $10 \mathrm{pmol} \mathrm{mol}^{-1}$ (the published value of $3 \mathrm{pmol} \mathrm{mol}^{-1}$ has to be revised following re-analysis of data using an up-to-data cross-section; A. Saiz-Lopez, pers. comm.). Peters et al. (2005), who used OIO absorption cross sections of Bloss et al. (2001), gave maximum OIO mixing ratios of $13.3 \mathrm{pmol} \mathrm{mol}^{-1}$ (Brittany) and $15.3 \mathrm{pmol} \mathrm{mol}^{-1}$ (North Sea) for a DOAS light path of nearly $20 \mathrm{~km}$, and $9.2 \mathrm{pmol} \mathrm{mol}^{-1}$ for a re-analysis of Mace Head data (see Table 3 of Peters et al., 2005). However, due to high residual structures in the $500-600 \mathrm{~nm}$ spectral region used for OIO analysis, these values were always close to the detection limit, and the identification of OIO therefore very uncertain. According to a preliminary evaluation of the DOAS measurements during the ICARTT campaign, significant amounts of up to $40 \mathrm{pmol} \mathrm{mol}^{-1}$ OIO were detected at Appledore Island (J. Stutz, pers. comm.). Hence, there are still considerable uncertainties and possibly large spatial variations regarding OIO levels in the atmosphere. We would 

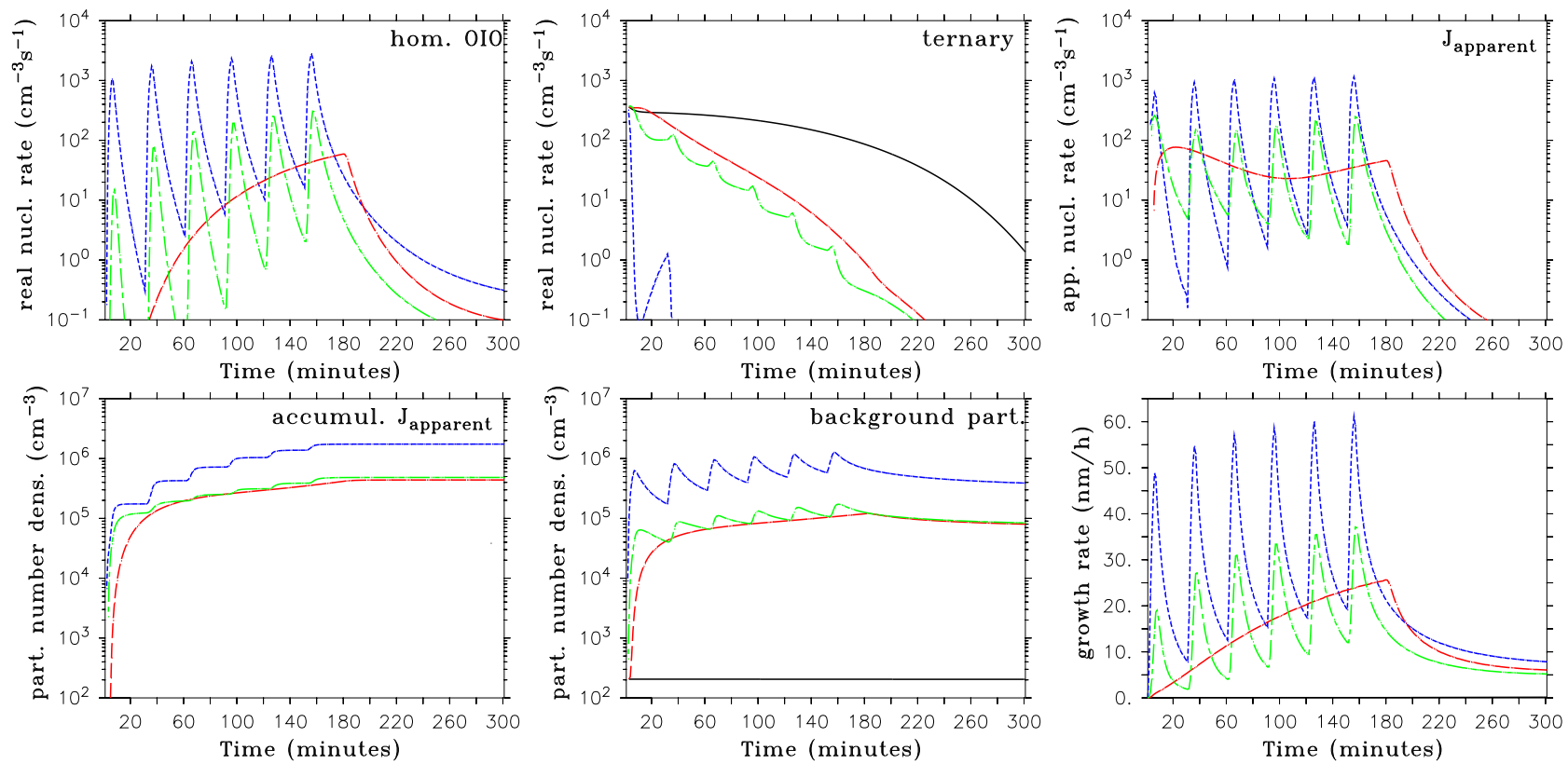

Fig. 6. 5-h timeseries of real and apparent nucleation rates, the accumulated apparent nucleation rate, total background particle number density, and the nuclei growth rate at $15 \mathrm{~m}$ altitude for different scenarios for the marine case: scenario 0 (black - solid), scenario 1 (red dashed), scenario 2 (green - dash-dotted), scenario 3 (blue - dotted). All model runs start at local noon.

also like to note that an overestimation of OIO mixing ratios in our model simulations is possible as we neglect in our reaction mechanism any potential intermediate compounds between $\mathrm{OIO}$ and stable $\mathrm{OIO}$ clusters (i.e., $\mathrm{I}_{\mathrm{x}} \mathrm{O}_{\mathrm{y}}$ with $\mathrm{x}, \mathrm{y}>1$ ). A respective sensitivity estimate is presented in Sect. 4.4.

The homogeneous OIO nucleation rates increase with increasing OIO mixing ratios (Fig. 6, note the logarithmic yaxis), reaching a maximum of about 60 nuclei $\mathrm{cm}^{-3} \mathrm{~s}^{-1}$ after $3 \mathrm{~h}$ in the continuous emissions case. Ternary $\mathrm{H}_{2} \mathrm{SO}_{4}-\mathrm{NH}_{3}-$ $\mathrm{H}_{2} \mathrm{O}$ nucleation rates are of the same order of magnitude, but in contrast to OIO nucleation rates they decrease with time following the temporal evolution of sulfuric acid in the model (Fig. 5): The decrease in sulfuric acid is due to the fact that (1) $\mathrm{H}_{2} \mathrm{SO}_{4}$ mixing ratios are at a maximum around noon (i.e., at the beginning of the scenario), and (2) $\mathrm{H}_{2} \mathrm{SO}_{4}$ is being taken up by the newly formed particles. Hence, in the continuous emission case the model predicts similar nucleation rates for both applied "real" nucleation mechanisms, ternary nucleation being more important at the beginning, homogeneous OIO nucleation at the end of the 3 model hours with iodine emissions.

This is also evident in the "apparent" nucleation rates which have two maxima after about half an hour and 3 hours, reaching nearly 100 particles $\mathrm{cm}^{-3} \mathrm{~s}^{-1}$. Hence, a large part of the nuclei indeed grows to detectable sizes. That is, OIO mixing ratios are high enough to let the nuclei grow with a rate (up to $25 \mathrm{~nm} / \mathrm{h}$ ) sufficient to overcome significant scavenging by background particles. Apparent nucleation increases the background particle number density to about
$10^{5}$ particles $\mathrm{cm}^{-3}$ after $3 \mathrm{~h}$. Due to vertical mixing and sedimentation this number is less than the accumulated number of newly formed particles, but it is likely to be an overestimate since MISTRA does not include coagulation. Background particle surface area increases from $70 \mu \mathrm{m}^{2} \mathrm{~cm}^{-3}$ to a maximum of $140 \mu \mathrm{m}^{2} \mathrm{~cm}^{-3}$. For the continuous emission case it can be concluded that in the clean marine environment OIO can both contribute to the formation of new particles and their subsequent condensational growth, and may enhance particle number densities after a while. However, this scenario cannot explain observed particle "burst", where particle number densities increase drastically in quite a short time period.

If the same total amount of alkyl iodides is emitted in hot spots instead of continuously (compare the green and red lines of Figs. 5 and 6), peak values of organoiodides rise up to $10 \mathrm{pmol} \mathrm{mol}^{-1}\left(\mathrm{CH}_{2} \mathrm{I}_{2}\right)$. Modeled peak IO and OIO mixing ratios are $7 \mathrm{pmol} \mathrm{mol}^{-1}$ and about $20 \mathrm{pmol} \mathrm{mol}^{-1}$, respectively. These relatively high peak values are not in contradiction to available observations because hot spots are very difficult to detect in field campaigns. Especially active longpath DOAS that has widely been used to measure IO and OIO fails to resolve hot spots because it measures the total number of molecules along the DOAS lightpath but not their horizontal distribution. Homogeneous OIO nucleation rates, which depend nonlinearily on OIO mixing ratios, are considerably higher in the "hot spot" case, reaching peak values up to 300 nuclei $\mathrm{cm}^{-3} \mathrm{~s}^{-1}$ (Fig. 6). Pulse emissions of alkyl iodides especially lead to a faster increase in particle number 

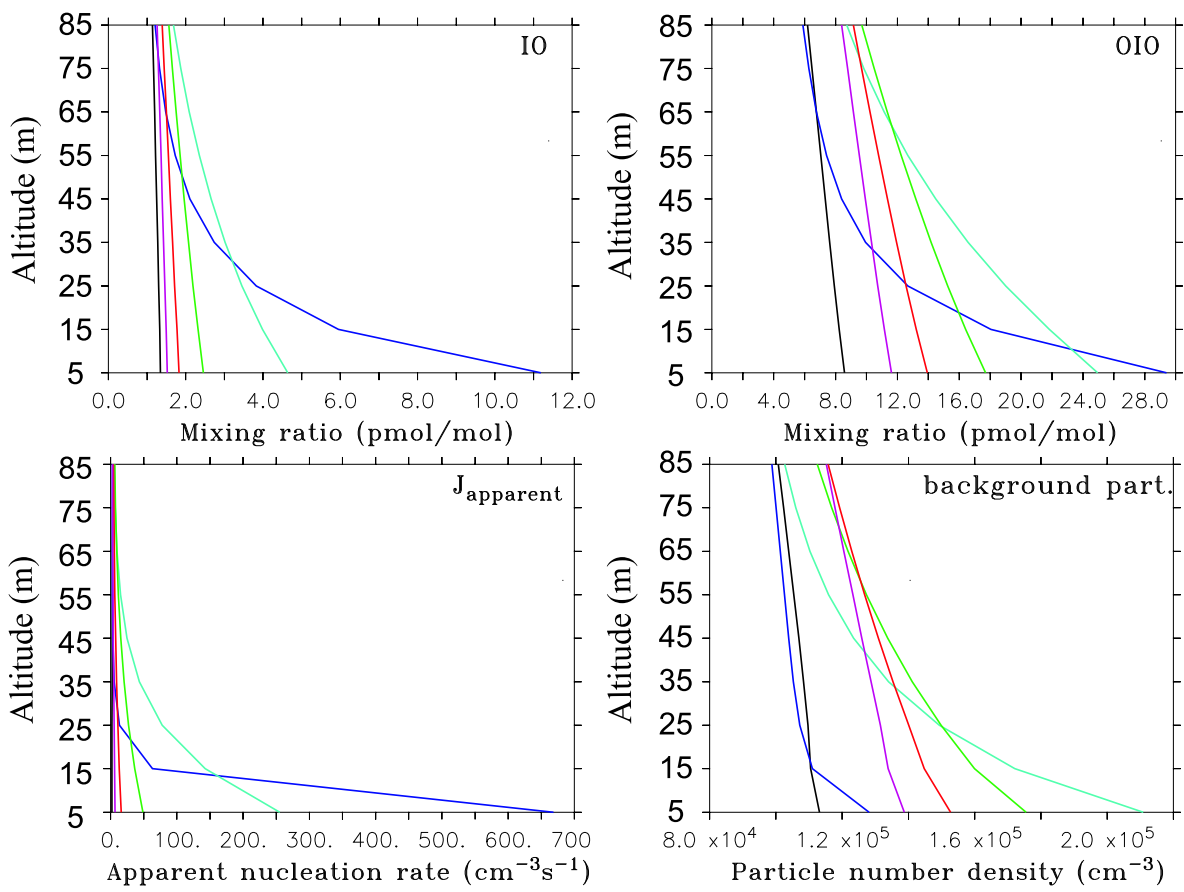

Fig. 7. Vertical profiles of IO and OIO mixing ratios as well as apparent nucleation rates and background particle number densities for the clean marine scenario 2. Vertical profiles are plotted with a time gap of 5 min each, beginning at the onset of the last (6th) emissions peak at 14:30 in the order black/dark blue/turquoise/green/red/purple.

density, which is in better agreement with the observations of nucleation "bursts". Even the first hot spot of our scenario increases particle number densities to $6 \cdot 10^{4} \mathrm{~cm}^{-3}$, i.e., one hot spot of alkyl iodide emissions could be responsible for a significant enhancement of background particle numbers via homogeneous nucleation and subsequent particle growth by $\mathrm{OIO}$, at least in a very clean marine background atmosphere.

If we include molecular iodine in the list of species emitted during low tide adjusting the flux according to the nighttime accumulation as described above, we end up with peak $\mathrm{I}_{2}$ mixing ratios of less than $1 \mathrm{pmol} \mathrm{mol}^{-1}$ at $15 \mathrm{~m}$ altitude during midday (Fig. 5, blue lines), which is below the DOAS detection limit for molecular iodine (Peters et al., 2005). Directly above the surface, $I_{2}$ mixing ratios reach up to $10 \mathrm{pmol} \mathrm{mol}^{-1}$. The small modeled $\mathrm{I}_{2}$ mixing ratios during daytime result from its short photolytic lifetime of about $10 \mathrm{~s}$. Despite these barely detectable gas phase concentrations of $\mathrm{I}_{2}$, the effect on IO and OIO mixing ratios is large, namely an increase of peak values by nearly a factor of two. At the same time, maximum OIO nucleation rates increase by an order of magnitude up to 3000 nuclei $\mathrm{cm}^{-3} \mathrm{~s}^{-1}$. Ternary nucleation ceases since $\mathrm{H}_{2} \mathrm{SO}_{4}$ is quickly taken up by the strongly increased background particle number, making OIO nucleation the only important mechanism for new particle formation. Apparent nucleation rates reach $10^{3}$ particles $\mathrm{cm}^{-3} \mathrm{~s}^{-1}$, increasing particle number density to nearly $10^{6}$ particles $\mathrm{cm}^{-3}$ within 5 min. Hence, this mechanism could explain even large particle bursts in a clean marine boundary layer, OIO being the only responsible species for both new particle formation and their subsequent growth. However, our study indicates that particle bursts observed at Mace Head, where nucleation rates of about $10^{5}-10^{7}$ nuclei $\mathrm{cm}^{-3} \mathrm{~s}^{-1}$ seem to be required to explain the observations (O'Dowd et al., 1999; Pirjola et al., 2002), cannot entirely be due to homogeneous OIO nucleation.

For hot spot-like distributed sources, a useful comparison of model results and field observations is difficult due to gradients in the vicinity of the hot spots. For illustration, Fig. 7 shows vertical profiles for IO, OIO, apparent nucleation rate and the particle number density of scenario 2 for different time lags after the last (i.e., 6th) hot spot. Vertical profiles are plotted every $5 \mathrm{~min}$, starting at the onset of the last hot spot emissions in the model. Expressed in equivalent horizontal distance, $5 \mathrm{~min}$ would resemble $1.8 \mathrm{~km}$ for a horizontal wind speed of $6 \mathrm{~m} / \mathrm{s}$ (which is the horizontal $10 \mathrm{~m}$ wind speed in the model).

With the beginning of the hot spot emissions, mixing ratios of IO and OIO sharply increase especially near the surface. After reaching a maximum, concentrations decrease again in both horizontal and vertical distances. In case of shortlived IO, mixing ratios decrease from a maximum value of about $11 \mathrm{pmol} \mathrm{mol}^{-1}$ directly above the hot spot to about $5 \mathrm{pmol} \mathrm{mol}^{-1}$ at $20 \mathrm{~m}$ altitude. In horizontal distance, 5 min after the maximum, mixing ratios decreased below 5 pmol mol${ }^{-1}$ everywhere. Therefore, mean IO mixing ratios inferred from longpath-DOAS masurements can in most 

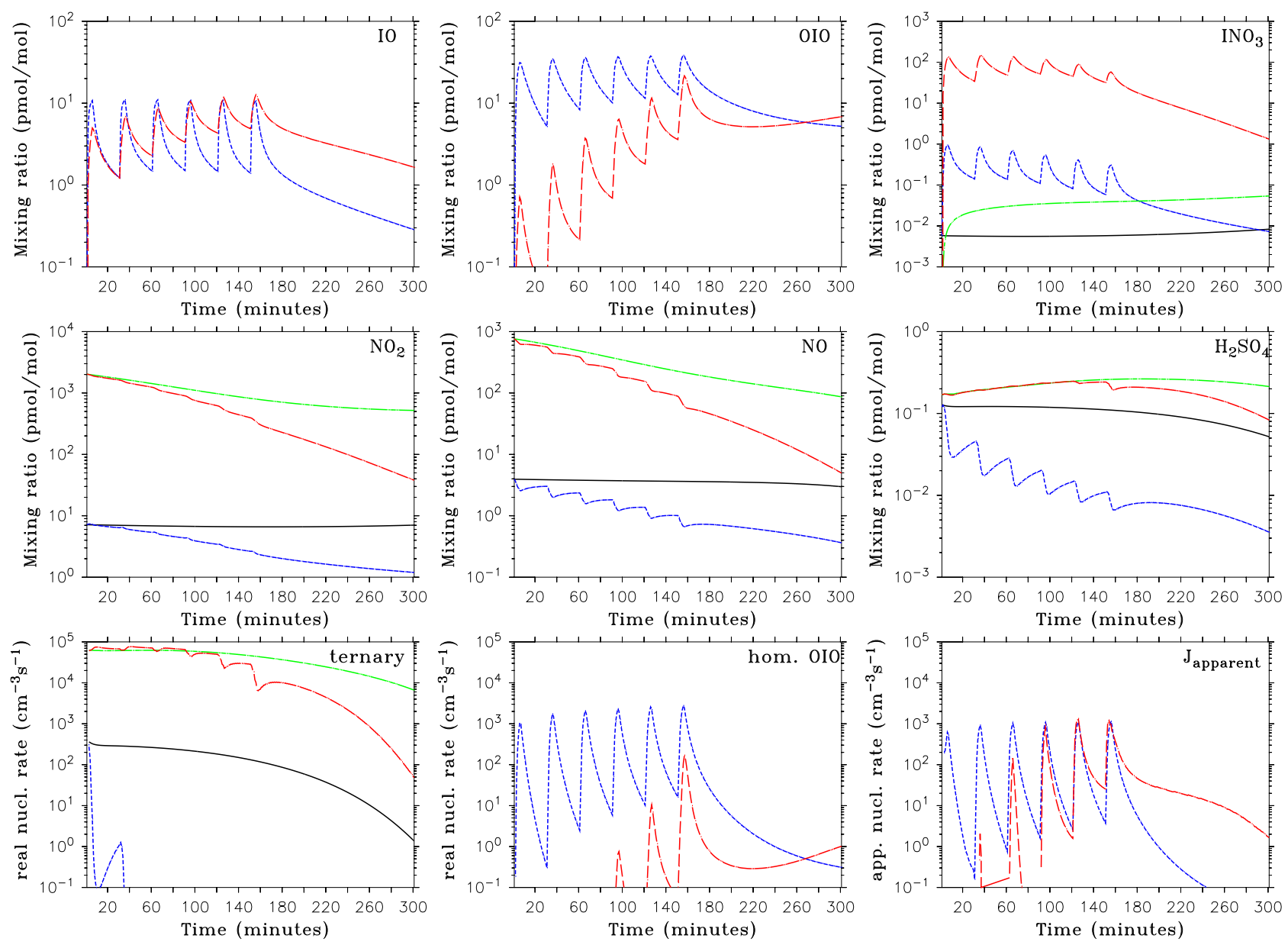

Fig. 8. 5-h timeseries of mixing ratios of important gas phase species at $15 \mathrm{~m}$ altitude for scenario 3 for the marine and the continental case: marine (blue - dotted), continental (red - dashed). The base case scenario 0 has been added for comparison where reasonable: marine (black - solid), continental (green - dash-dotted). All model runs start at local noon. Note the logarithmic y-axis.

cases be expected to be considerably lower than mixing ratios directly above correlated hot spots: For example, even if a hot spot of the kind assumed in our model studies were located directly below the DOAS light path and the wind velocity were $6 \mathrm{~m} / \mathrm{s}$ parallel to it (i.e., the mean can be inferred from our model study as integral of IO mixing ratios along the light path), a DOAS instrument with assumed $16 \mathrm{~km}$ (i.e., $2 \times 8 \mathrm{~km}$ ) light path $15 \mathrm{~m}$ above the ground would find a mean mixing ratio of only about $3 \mathrm{pmol} \mathrm{mol}^{-1} \mathrm{IO}$, which is nearly a factor of 4 lower than the maximum mixing ratio directly above the hot spot. Alternative conditions, i.e., different wind directions or hot spots at further distance from the instrument, would make detection of large amounts of IO even more unlikely. For OIO, the model predicts a slower decrease, implying that OIO could be more easily detected than IO further away from the source. Note that this result is qualitatively only true for a photolytic lifetime of OIO of at least tens of seconds (for sensitivity studies see Sect. 4.4).
Regarding the detection of new particle formation, Fig. 7 shows a very strong decrease in nucleation rates with increasing distance from the hot spot. However, since the quantity measured is not the nucleation rate itself but rather background particle numbers, particle bursts should still be detectable whithin a distance of several hundred meters from the hot spot (as increased number density), because according to our model simulations increased particle numbers are conserved for a while in the clean marine environment. However, once again we want to point out the restriction that MISTRA does neither account for coagulation nor for horizontal dilution of particles and may therefore underestimate the speed with which number densites decrease downwind of the hot spots.

\subsection{Clean marine versus polluted continental background}

The conclusions drawn from the model runs assuming a clean marine background atmosphere are of course not necessarily true for different air masses such as the one we 

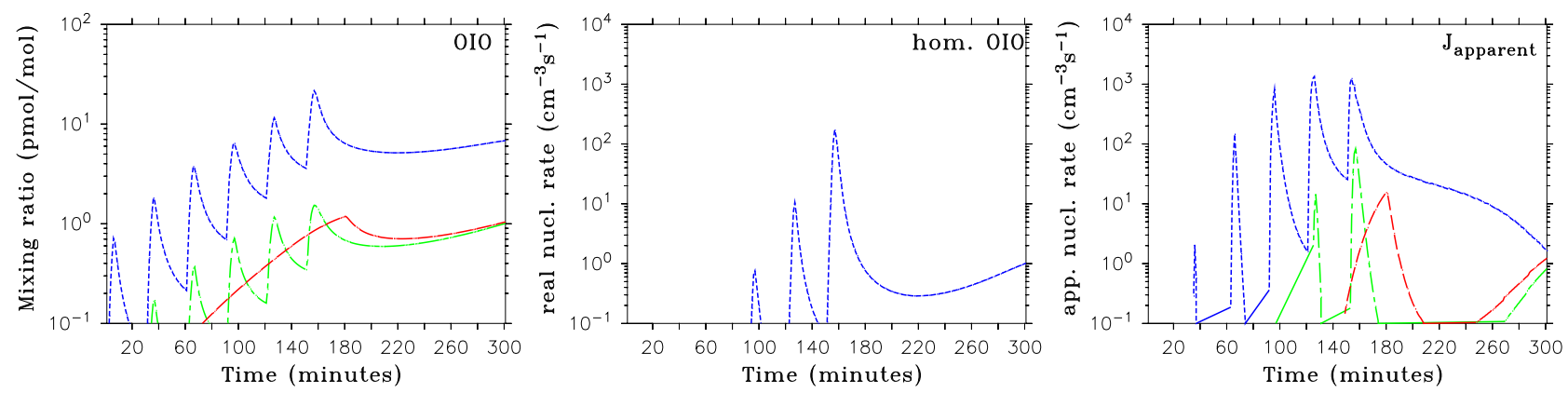

Fig. 9. 5-h timeseries of mixing ratios of important gas phase species at $15 \mathrm{~m}$ altitude for scenarios 1 to 3 for the continental case: scenario 0 (black - solid), scenario 1 (red - dashed), scenario 2 (green - dash-dotted), scenario 3 (blue - dotted). All model runs start at local noon.

assume for our polluted continental cases. Figure 8 shows 5-h timeseries of scenario 3 (Table 3) for the marine (blue lines) and the continental runs (green lines). The polluted atmosphere is, compared to the marine case, characterized by two orders of magnitude higher $\mathrm{NO}_{\mathrm{x}}$ mixing ratios (some nmol $\mathrm{mol}^{-1}$ ), and one order of magnitude higher $\mathrm{SO}_{2}$ mixing ratios (see Table 2). Not surprisingly, the ternary nucleation parameterization routine predicts much higher ternary nucleation rates, mainly due to higher gas phase concentrations of sulfuric acid, of up to nearly $10^{5}$ nuclei $\mathrm{cm}^{-3} \mathrm{~s}^{-1}$. Due to high $\mathrm{NO}_{2}$, the reaction $\mathrm{IO}+\mathrm{NO}_{2} \longrightarrow \mathrm{INO}_{3}$ becomes more important, increasing the sink for IO and drastically increasing mixing ratios of $\mathrm{INO}_{3}$ from less than $1 \mathrm{pmol} \mathrm{mol}^{-1}$ in the marine case to up to $200 \mathrm{pmol} \mathrm{mol}^{-1}$. At the same time, the reaction rates for the reaction $\mathrm{OIO}+\mathrm{NO} \longrightarrow \mathrm{IO}+\mathrm{NO}_{2}$ increase due to enhanced NO mixing ratios, increasing the sink for OIO and enhancing the production of IO. Hence, OIO mixing ratios are low as long as high $\mathrm{NO}$ mixing ratios prevail in the model runs. Interestingly, the mixing ratio of IO is comparable in magnitude to the marine run, meaning that IO destruction by $\mathrm{IO}+\mathrm{NO}_{2}$ is roughly counterbalanced by IO production via $\mathrm{OIO}+\mathrm{NO}$. This seems to be in accordance with field measurements, where $\mathrm{IO}$ could be observed also under high- $\mathrm{NO}_{\mathrm{x}}$ conditions (Brittany, Peters et al., 2005; Appledore Island, J. Stutz, pers. comm.). However, OIO data from Appledore Island do not indicate a clear correlation with atmospheric $\mathrm{NO}_{\mathrm{x}}$ levels either, which is in contradiction to the model simulations, indicating further open questions regarding processes involving OIO.

The considerably lower OIO mixing ratios in the polluted model run lead to drastically lower related nucleation rates: In the beginning of the scenario, as long as OIO ranges below about $5 \mathrm{pmol} \mathrm{mol}^{-1}$, homogeneous OIO nucleation is unimportant for the prevailing temperatures of around $290 \mathrm{~K}$. Only at the 5th and 6th hot spot, nucleation rates reach peak values of up to 10 and 100 nuclei $\mathrm{cm}^{-3} \mathrm{~s}^{-1}$, respectively, but only for timescales of some minutes. Compared to the 3 orders of magnitude larger ternary nucleation rates, homogeneous OIO nucleation can be regarded as unimportant for polluted atmospheres such as the one considered here.

However, OIO does contribute to the growth of nuclei, at least after OIO mixing ratios exceed about $3 \mathrm{pmol} \mathrm{mol}^{-1}$ : Apparent nucleation rates reach peak values up to 200 particles $\mathrm{cm}^{-3} \mathrm{~s}^{-1}$ in the 3rd hot spot and up to 1000 particles $\mathrm{cm}^{-3} \mathrm{~s}^{-1}$ in the following hot spots. Note that the latter value is comparable to apparent nucleation rates in the marine case, but that the fraction of the nuclei that grow from cluster size to detectable sizes is much smaller. In reality, apparent nucleation rates may even be larger than predicted by our model since for the large number of ternary formed nuclei self-coagulation among them may contribute considerably to cluster growth (Kerminen et al., 2004). Furthermore, it is possible that other iodine species, e.g. HOI, could contribute to early particle growth (O'Dowd et al., 2002b). We investigate this with scenario 7, where we hypothetically assume HOI to contribute to early particle growth. This leads in the simulations to a reduction of HOI peak values from $50 \mathrm{pmol} \mathrm{mol}^{-1}$ (scenario 3) to $20 \mathrm{pmol} \mathrm{mol}^{-1}$ (scenario 7) at $15 \mathrm{~m}$ altitude, to higher apparent nucleation rates of up to 2000 particles $\mathrm{cm}^{-3} \mathrm{~s}^{-1}$, and especially to an earlier onset of nucleation already within the first hotspot (not shown).

Up to now, for the polluted case we have only discussed scenarios, which are characterized by large emissions of reactive iodine precursors (scenario 3). For scenarios 1 and 2, i.e., without emissions of $\mathrm{I}_{2}$, the model predicts OIO mixing ratios of less than $2 \mathrm{pmol} \mathrm{mol}^{-1}$ and negligible homogeneous nucleation rates (Fig. 9). The apparent nucleation rates reach spikes of up to 100 particles $\mathrm{cm}^{-3} \mathrm{~s}^{-1}$ in the hot spot emission case, and even considerably smaller values for the continuous emission scenario. Although OIO contributes less to nuclei growth in these cases than in the respective clean marine cases, this contribution is still larger than the contribution from sulfuric acid: Scenario 6, where we assume nuclei growth not only by OIO but also by $\mathrm{H}_{2} \mathrm{SO}_{4}$ (see Table 3 ), shows that the mixing ratios of less than $1 \mathrm{pmol} \mathrm{mol}^{-1}$ $\mathrm{H}_{2} \mathrm{SO}_{4}$ in our model runs are not enough to significantly enhance apparent nucleation rates (not shown). 

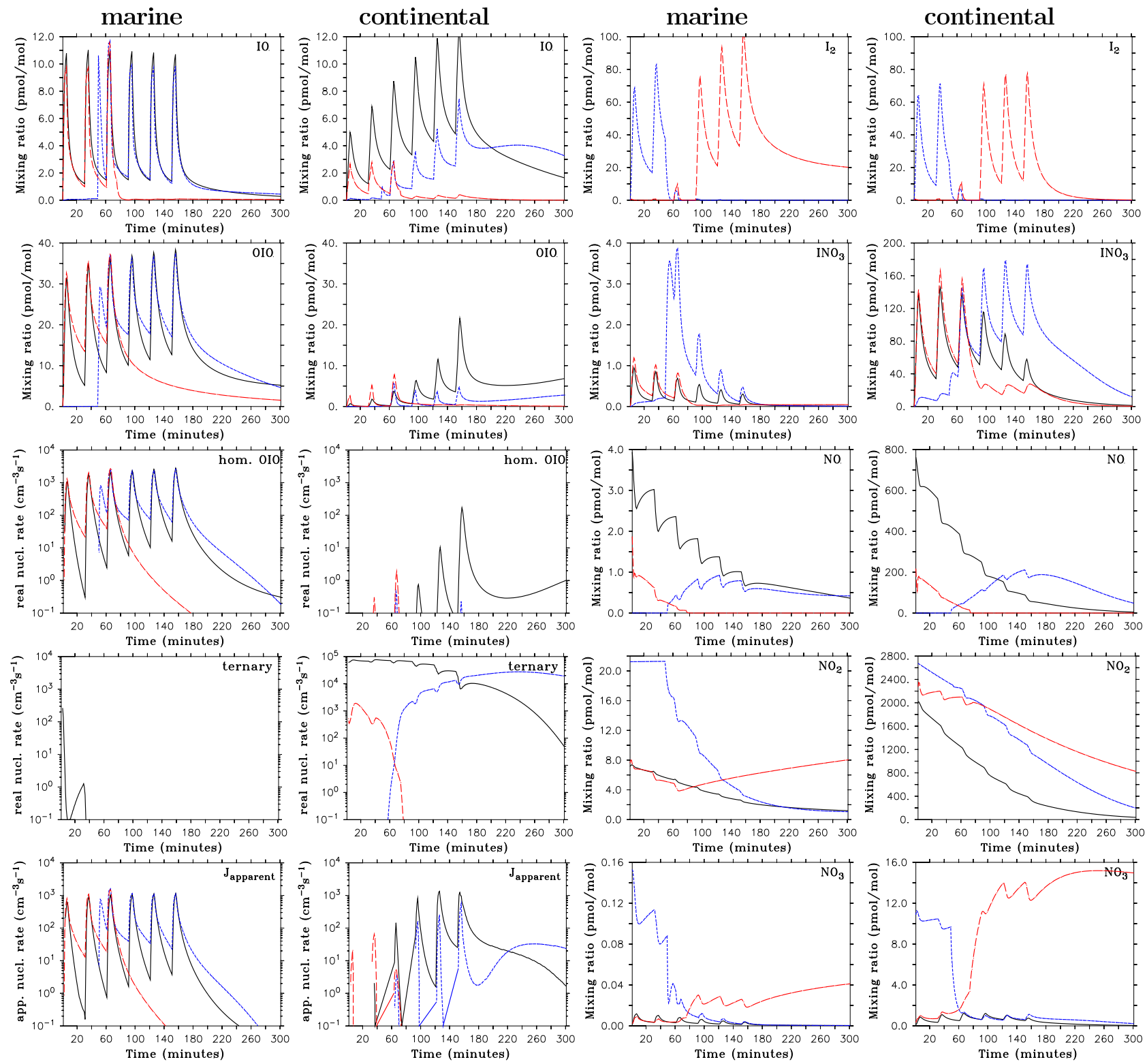

Fig. 10. 5-h timeseries of mixing ratios of important gas phase species and nucleation properties at $15 \mathrm{~m}$ altitude for scenarios 3 (model start local noon - black, solid), 4 (model start 04:00 - blue, dotted), 5 (model start 18:00 - red, dashed) for the marine (left) and the continental (right) case.

The conclusions that can be drawn from this are as follows: First, particle production involving iodine compounds seems to be less important for polluted background atmospheres than for clean atmospheres because ternary $\mathrm{H}_{2} \mathrm{SO}_{4}$ $\mathrm{NH}_{3}-\mathrm{H}_{2} \mathrm{O}$ nucleation rates are lower and $\mathrm{OIO}$ mixing ratios are higher in a clean atmosphere. Regarding the latter, uncertainties remain with respect to the dependence of OIO mixing ratios on atmospheric $\mathrm{NO}_{\mathrm{x}}$ levels. Second, higher OIO concentrations are necessary for new nuclei formation than are necessary to contribute to the growth of pre-existing clusters. In other words, our studies suggest that OIO more easily con- tributes to nuclei growth than to new nuclei formation. The role of sulfuric acid is the opposite: Its concentration is large enough for significant ternary nucleation rates, even though it is not sufficient to contribute significantly to early cluster growth.

\subsection{Diurnal variability}

All scenarios discussed so far started at local noon, extending over 5 hours until 17:00 local time. In order to investigate the influence of solar irradiance on our results, we performed additional scenarios, starting at 04:00 and 18:00, respectively. 

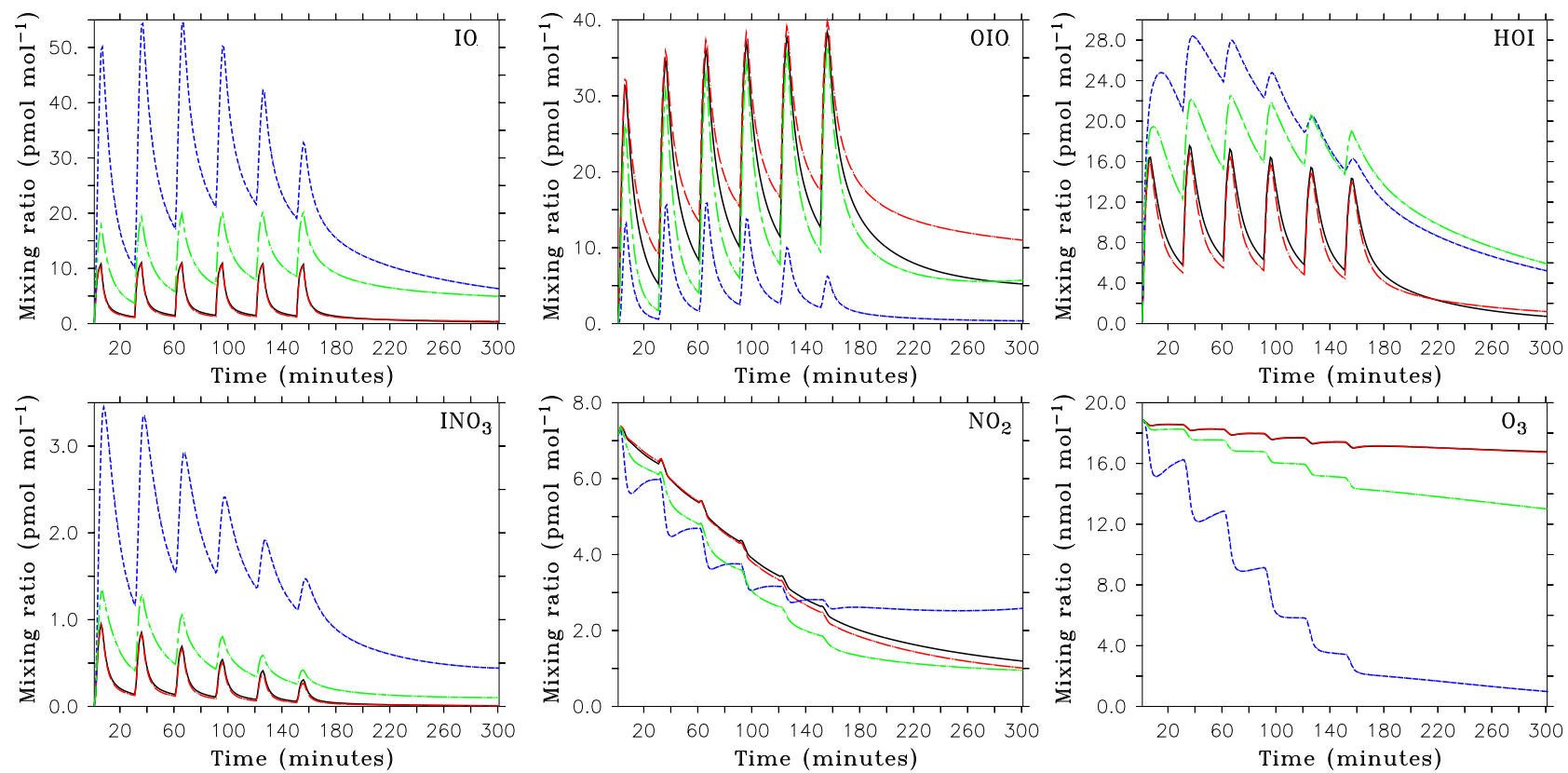

Fig. 11. 5-h timeseries of mixing ratios of important gas phase species at $15 \mathrm{~m}$ altitude for scenario 3 (black - solid), scenario 8 (red dashed), scenario 9 (blue - dotted), scenario 10 (green - dash-dotted) for the marine case. All scenarios start at local noon.

Sunrise is at 04:45, and sunset at 19:15 under the chosen conditions. Figure 10 shows results for the "morning" scenario 4 and the "evening" scenario 5 compared to the noon scenario 3 (see Table 3) for both the clean marine and the polluted continental case.

In the marine case mixing ratios of IO are quite independent of local time as long as sunlight is present, while in the continental case significantly lower IO mixing ratios are modeled for the morning and evening scenarios. This is mainly due to higher $\mathrm{NO}_{2}$ mixing ratios at the beginning or end of the day in the polluted scenarios, making the formation of $\mathrm{INO}_{3}$ a more efficient sink for IO. While in the marine scenario IO mixing ratios quickly approach zero after sunset, IO maxima (though much smaller than during day) are still visible in the polluted case coinciding with hot spot emission peaks: In a high- $\mathrm{NO}_{\mathrm{x}}$ atmosphere, some IO is produced via $\mathrm{I}_{2}+\mathrm{NO}_{3} \longrightarrow \mathrm{INO}_{3}$ followed by the thermal decomposition of $\mathrm{INO}_{3} \longrightarrow \mathrm{IO}+\mathrm{NO}_{2}$ as suggested by Saiz-Lopez and Plane (2004).

Regarding OIO, in the marine case mixing ratios reach about the same peak values in the morning and evening scenarios as in the noon scenario, but minimum values between the emission pulses are larger due to lower NO mixing ratios, making the sink for OIO via OIO+NO less efficient. This also holds for the polluted evening case, where during the first three emission pulses OIO mixing ratios exceed the values for the noon case although IO mixing ratios (and hence the formation rate of OIO) is lower. At night, near-surface OIO concentrations mainly decrease via deposition, vertical mixing, and uptake into aerosol.
Nucleation rates for the morning and evening scenarios exhibit some differences compared to those starting at noon: In the marine case, ternary nucleation is completely unimportant in the morning and evening due to the daily-cycle related low $\mathrm{H}_{2} \mathrm{SO}_{4}$ mixing ratios. In contrast, homogeneous OIO nucleation rates are higher than during noon, following the larger OIO mixing ratios. Hence, in the marine case OIO nucleation can be regarded as the only important nucleation mechanism in the morning and evening hours. In the polluted case, ternary nucleation rates are also lower in the morning and evening than during midday, but significantly larger than the negligible OIO nucleation rates. Nevertheless, apparent nucleation rates due to OIO still reach up to $1000 \mathrm{nu}-$ clei $\mathrm{cm}^{-3} \mathrm{~s}^{-1}$. To summarize, for a clean marine background atmosphere, homogeneous OIO nucleation should be most important some time after sunrise or before sunset, when OIO mixing ratios are largest due to low $\mathrm{NO}$ and when sulfuric acid concentrations are small. For a polluted background atmosphere, nuclei formation by OIO nucleation seems to be unimportant compared to ternary $\mathrm{H}_{2} \mathrm{SO}_{4}-\mathrm{NH}_{3}-\mathrm{H}_{2} \mathrm{O}$ nucleation at any time of the day, but OIO contributes to early nuclei growth if mixing ratios exceed some $\mathrm{pmol} \mathrm{mol}^{-1}$ (most likely shortly after sunset or before sunrise, or via accumulation of OIO when air moves over more than one hot spot).

An interesting feature of our morning simulation is a "sunrise peak" that does not coincide with the emission pulses, evident e.g., in $\mathrm{IO}, \mathrm{OIO}, \mathrm{INO}_{3}$, and the homogeneous OIO nucleation rate especially in the clean marine, but also slightly in the polluted continental model run (Fig. 10). This peak is due to accumulation of molecular iodine (and to a 

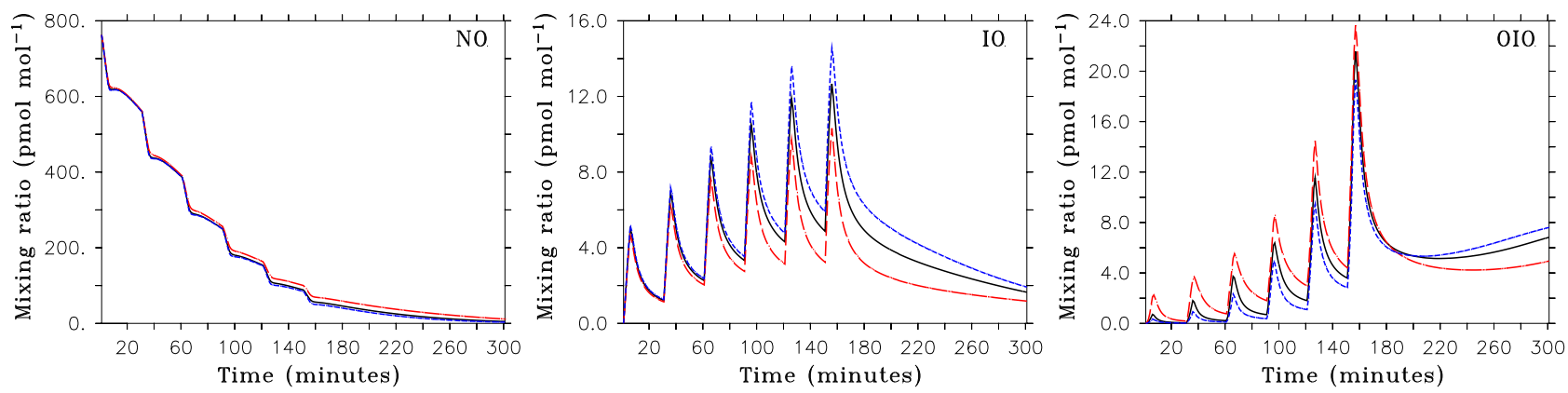

Fig. 12. 5-h timeseries of mixing ratios of important gas phase species at $15 \mathrm{~m}$ altitude for scenario 3 (black - solid), scenario 12 (red dashed), scenario 13 (blue - dotted) for the continental case. All scenarios start at local noon.

smaller extent also $\mathrm{CH}_{2} \mathrm{I}_{2}$ ) emitted during night, which is quickly photolyzed after sunrise, producing a sharp increase in I radicals and therefore IO and OIO. In other words, peaks of these compounds shortly after sunrise should not necessarily be expected to correlate with low tide during field campaigns, because they may simply arise from accumulation of reactive iodine precursors with a short photolytic lifetime (e.g., $\mathrm{CH}_{2} \mathrm{I}_{2}, \mathrm{I}_{2}$ ) during nighttime.

\subsection{Sensitvity regarding OIO chemistry}

There are two reactions involving OIO in our mechanism that are especially uncertain, i.e., the reaction $\mathrm{OIO}+\mathrm{OH}$ and the photolysis of OIO as possible sinks for OIO. Regarding the first reaction, only a rough estimate exists (von Glasow et al., 2002a). The photolysis of OIO has been discussed with quite controversal results (Ingham et al., 2000; Ashworth et al., 2002). Mainly as a result of the THALOZ (2005) project, the laboratories who published the two studies on OIO photolysis agree on a rather low quantum yield of less than $10 \%$. However, due to strong absorption bands of OIO even a small quantum yield could make photolysis the dominant sink for OIO (see below). Further uncertainties regard the exact product yields of the IO self-reaction (see Table 1), as well as the reaction rate constant of $\mathrm{OIO}+\mathrm{NO}$, which was provided by THALOZ (2005) with an uncertainty range of $0.9-11.3 \times 10^{-13} \mathrm{e}^{712 / T} \mathrm{~cm}^{3} \mathrm{~s}^{-1}$.

In our studies presented so far, we assumed OIO being photolytically stable, and we included the reaction of OIO with $\mathrm{OH}$ according to von Glasow et al. (2002a). We furthermore assumed the self-reaction of IO to yield OIO+I $(100 \%)$. In order to test the sensitivity of our results to these assumptions, we performed model runs without the reaction $\mathrm{OIO}+\mathrm{OH}$ (scenario 8 ), or assuming $\mathrm{IO}+\mathrm{IO} \longrightarrow 0.8$ $\mathrm{OIO}+1.2 \mathrm{I}+0.2 \mathrm{O}_{2}$ (scenario 11), or including OIO photolysis (scenarios 9, 10). In scenario 9, we use the upper limit of Saiz-Lopez et al. (2005), who computed the photolysis rate to be $0.48 \mathrm{~s}^{-1}$ for clear sky conditions during local noon at $53^{\circ} \mathrm{N}$ in July, assuming the quantum yield to be $100 \%$ across all absorption bands between 480 and $650 \mathrm{~nm}$. We use this value to adjust noontime OIO photolysis rates in the model, assuming the same spectral dependencies as for $\mathrm{OClO}$ photolysis. In scenario 10 , we scale photolysis rates by a factor of 0.05 in order to account for a lower quantum yield of $5 \%$. Hence, the photolytic lifetime of OIO is about $2 \mathrm{~s}$ (scenario 9 ) and $40 \mathrm{~s}$ (scenario 10) at local noon in our simulations.

For the clean marine case, photolysis of OIO as assumed in both our sensitivity studies, is by far the most important sink for gas phase OIO: Even for the more moderate scenario 10 the lifetime of OIO with respect to photolysis is by a factor of about 180 smaller than with respect to the reaction with NO, and by a factor of about 30 smaller than with respect to the reaction with $\mathrm{OH}$. In the polluted continental case with $\mathrm{NO}$ mixing ratios being higher by about two orders of magnitude, the lifetimes with respect to photolysis (scenario 10) and the reaction with $\mathrm{NO}$ are of similar magnitudes. As photolysis is more important in a clean than a polluted air mass, we restrict our investigations to the clean marine case in the following.

Figure 11 shows 5-hour timeseries for scenarios 8, 9, and 10 compared to scenario 3 (see Table 3). Excluding the reaction $\mathrm{OIO}+\mathrm{OH}$ leads to an increase in $\mathrm{OIO}$ mixing ratios, to a lack of the formation of $\mathrm{HIO}_{3}$ (which is implemented as an unreactive sink for OIO), and to a slight decrease in HOI. The effects on IO, as well as $\mathrm{NO}_{\mathrm{x}}$ and ozone mixing ratios are negligible. The exclusion of the reaction $\mathrm{OIO}+\mathrm{OH}$ has little effect on gas phase chemistry, but increases OIO-based nucleation rates due to enhanced gas phase OIO mixing ratios, and decreases $\mathrm{IO}_{3}^{-}$formation in the aerosol. The change in product yields of the IO self-reaction (scenario 11) has a negligible effect on atmospheric chemistry (not shown). I and IO change by less than $1 \mathrm{pmol} \mathrm{mol}^{-1}$, the effect on OIO is even smaller.

Including OIO photolysis into the model shows a large impact on atmospheric chemistry: OIO photolyzes to $\mathrm{I}+\mathrm{O}_{2}$, where the I radicals quickly react with ozone to produce IO. The depletion of ozone due to this reaction cycle is significant: For the moderate scenario 10, ozone mixing ratios decrease by $6 \mathrm{nmol} \mathrm{mol}^{-1}$ within $5 \mathrm{~h}$, for the extreme scenario 9 ozone is nearly completely destroyed within the same time period. Furthermore, IO mixing ratios strongly increase if 
OIO is assumed to photolyze, by a factor of about 2 in scenario 10 , and even a factor of 5 in scenario 9 , reaching peak values of $55 \mathrm{pmol} \mathrm{mol}^{-1}$. Higher IO mixing ratios also enhance the formation of $\mathrm{HOI}$ and $\mathrm{INO}_{3}$, leading to an increase in these species and a slight decrease in $\mathrm{NO}_{\mathrm{x}}$ mixing ratios. The changes in OIO mixing ratios themselves are less pronounced than changes in IO mixing ratios, especially for the moderate scenario 10: The destruction of OIO due to photolysis is partly counteracted by an enhanced production via the self reaction of IO. Our results suggest that even in the case of a very short photolytic lifetime of only about $2 \mathrm{~s}$ (scenario 9), atmospheric OIO mixing ratios could reach detectable levels. However, the results of our extreme scenario 9 apparently are not in agreement with available observations, because a rapid ozone destruction has never been observed during field campaigns. This indicates that OIO has a likely photolytic lifetime of at least tens of seconds. Note, however, that this conclusion is only true if OIO mixing ratios are high enough and if there is no further sink reaction for OIO that has a similar reaction rate as photolysis but does not produce I radicals. For an equivalent scenario for the polluted continental case, where OIO mixing ratios are smaller and $\mathrm{OIO}+\mathrm{NO}$ is another important sink for OIO, ozone destruction is less, but still about $10 \mathrm{nmol} \mathrm{mol}^{-1}$ within $5 \mathrm{~h}$ (not shown).

Regarding the uncertainties of the reaction rate constant of $\mathrm{OIO}+\mathrm{NO}$, we performed additional sensitivity studies using the lower and upper limit provided by THALOZ (2005) (scenarios 12,13). As the importance of this reaction increases with increasing NO, model sensitivity runs are performed for the polluted continental case. The comparison with scenario 3 , where we use the best estimate reaction rate constant (see Table 1), shows that the effect on NO is negligible (Fig. 12). As expected, IO mixing ratios decrease while OIO mixing ratios increase for a lower reaction rate constant of OIO+NO, whereas for a larger reaction rate constant the opposite effect is visible. In the case of a slower sink reaction with NO, the relative increase in OIO is strongest for low mixing ratios (see first three peaks in Fig. 12).

Regarding potential intermediates between OIO and particles, there is evidence for the existence of compounds such as $\mathrm{I}_{2} \mathrm{O}_{3}, \mathrm{I}_{2} \mathrm{O}_{4}$, and $\mathrm{I}_{2} \mathrm{O}_{5}$ (Saiz-Lopez et al., 2005; Saunders and Plane, 2005), but the chemical kinetics of these compounds is still very poorly understood. Despite these uncertainties, we performed sensitivity studies including $\mathrm{I}_{2} \mathrm{O}_{3}$ and $\mathrm{I}_{2} \mathrm{O}_{4}$ in order to estimate their potential influence on atmospheric particle formation as well as on OIO mixing ratios (scenario 14). Reaction rate constants for the formation of $\mathrm{I}_{2} \mathrm{O}_{3}$ (via IO + $\mathrm{OIO}$ ) and $\mathrm{I}_{2} \mathrm{O}_{4}$ (via self-reaction of OIO), as well as the rate constant for the thermal decay of $\mathrm{I}_{2} \mathrm{O}_{4}$ are taken from Saunders and Plane (2005). If we assume that in addition to OIO, also $\mathrm{I}_{2} \mathrm{O}_{3}$ and $\mathrm{I}_{2} \mathrm{O}_{4}$ contribute to particle formation and early particle growth, real nucleation rates increase in the model, which is mainly due to the fact that the only known sink for $\mathrm{I}_{2} \mathrm{O}_{3}$ (which in contrast to $\mathrm{I}_{2} \mathrm{O}_{4}$ seems to be thermally stable) is particle formation. While in the clean marine case the increase in nucleation rates is relatively moderate (peak value increase from about 3000 to 4000 nuclei $\mathrm{cm}^{-3} \mathrm{~s}^{-1}$ ), the relative increase is stronger in the polluted continental case (increase from about 200 to 1000 nuclei $\mathrm{cm}^{-3} \mathrm{~s}^{-1}$ in the last hot spot) because the formation of $\mathrm{I}_{2} \mathrm{O}_{3}$ and $\mathrm{I}_{2} \mathrm{O}_{4}$ leads to a reduced loss of OIO by reaction with NO. OIO mixing ratios decrease drastically in the model due to formation of thermally stable $\mathrm{I}_{2} \mathrm{O}_{3}$ to peak values less than $5 \mathrm{ppt}$, i.e., OIO would not be detectable by DOAS measurements. Please note, however, that this estimate should be understood as very preliminary since the studies by Burkholder et al. (2004), which we used to set up the parameterization for OIO nucleation, relies on the assumption that OIO is the only nucleating and condensing species. Applying the parameterization to other iodine oxides (which we treat as "OIO equivalents" for nucleation) is strictly speaking beyond the validity range of the parameterization.

\section{Conclusions}

Our model sensitivity studies suggest that in a clean marine background atmosphere, OIO can significantly contribute both to homogeneous nuclei formation and to subsequent growth of particles to detectable sizes. If reactive iodine precursors are emitted in hot spots rather than continuously over a certain time (or space) the accumulated nucleation rate is larger, and particle number densities increase within a shorter time period. This indicates that observations of particle "bursts" are likely caused by hot spot-like emissions. Although emissions of alkyl iodides are sufficient for noticeable new particle formation by OIO in our clean scenarios, nucleation rates (both "real" and "apparent") are significantly enhanced by additional fluxes of molecular iodine, even if $\mathrm{I}_{2}$ mixing ratios range below $1 \mathrm{pmol} \mathrm{mol}^{-1}$ during daytime. Hence, $I_{2}$ is likely to be involved especially in strong particle bursts.

While even one hot spot of iodine emissions could be sufficient to significantly increase background particle numbers in a clean marine air mass, this is not the case in a polluted continental background atmosphere. In a polluted air mass containing some nmol mol${ }^{-1} \mathrm{NO}_{\mathrm{x}}$, gas phase OIO mixing ratios, and hence homogeneous OIO nucleation rates, are significantly lower than in a clean atmosphere. Compared to ternary $\mathrm{H}_{2} \mathrm{SO}_{4}-\mathrm{NH}_{3}-\mathrm{H}_{2} \mathrm{O}$ nucleation rates that may reach significant values in the polluted atmosphere, homogeneous OIO nucleation can be neglected. OIO only contributes to early particle growth in this case. In general, we found OIO to be more important for the growth of freshly formed particles than for the formation of new nuclei. $\mathrm{H}_{2} \mathrm{SO}_{4}$ mixing ratios as present in all our model studies are never sufficient to affect the growth of nuclei noticeably. Nevertheless, it is of course possible that other non- or low-volatile vapors such as HOI or organic compounds contribute to early particle growth. 
OIO mixing ratios and related nucleation rates tend to be higher close to sunset or sunrise than around noon due to lower NO mixing ratios. Our morning scenarios show a sunrise peak in species such as $\mathrm{IO}, \mathrm{OIO}, \mathrm{INO}_{3}$ or OIO nucleation rates, which is not correlated to the occurrence of hot spots, but which is caused by quick photolytic decomposition of reactive iodine precursors that accumulated during night (especially molecular iodine).

The sensitivity studies for the clean marine case show the best agreement with observations if $\mathrm{OIO}$ is assumed to be relatively stable against photolysis. If we, in contrast, assume a short photolytic lifetime of OIO of about $2 \mathrm{~s}$ around noon, ozone is nearly completely destroyed within $5 \mathrm{~h}$, which has never been observed during field campaigns. For an equivalent scenario for the polluted continental case, ozone destruction is less, but still about $10 \mathrm{nmol} \mathrm{mol}^{-1}$ within $5 \mathrm{~h}$.

The peak concentrations of IO and OIO in our simulations are not directly comparable to available observations, because hot spots are difficult to resolve during field campaigns. Instruments such as long-path DOAS provide mean values over several kilometers rather than peak values over hot spots. According to our simulations, especially IO mixing ratios decrease significantly both in vertical and horizontal direction from the hot spots (although horizontal mixing is not even included in our calculations). OIO should be more homogeneously distributed due to its longer chemical lifetime. Measurement sites and strategies should therefore be chosen carefully for future field campaigns. For example DOAS tomography, which allows for a spatial resolution of the measurement domain, could be a valuable tool for that purpose (Pundt et al., 2005).

There are still large uncertainties regarding both iodine chemistry and nucleation processes relevant for the atmosphere. While a lot of progress has been made during the last years with respect to gas phase iodine chemistry (e.g. THALOZ, 2005), there are considerable uncertainties regarding key reactions, e.g., photolysis rates of $\mathrm{OIO}$ or $\mathrm{INO}_{3}$. Even larger uncertainties exist regarding aqueous phase and heterogeneous reactions. Laboratory studies focusing on this aspect are urgently needed.

The parameterization of homogeneous OIO nucleation presented in the present paper is the first attempt to parameterize new nuclei formation via iodine oxides, and should certainly be improved with increasing knowledge about the exact nucleation mechanism in the future. Furthermore, the question should be addressed under which conditions nuclei formed by condensation of OIO could grow to sizes where they become important for radiative forcing or where they may act as cloud nuclei. The sensitivity studies presented here were set up for ambient conditions encountered during the ICARTT 2004 field campaign. A detailed comparison with ICARTT results (regarding iodine oxides, nucleation, etc.) will be addressed in future papers.
Acknowledgements. We want to thank V.-M. Kerminen, J. Crowley, J. Plane, and J. Stutz for their cooperation and helpful discussions, G. Carmichael and Y. Tang for providing data from their chemical transport model, and the whole ICARTT Appledore Island team for their support. This project was funded by the Deutsche Forschungsgemeinschaft DFG (Emmy Noether Junior Research Group MarHal GL 353/1-1). Additional travel funds were provided by the NSF (grant ATM04-01611). Contributions from E.R.L. and J.B.B. were funded in part by NOAA's Climate and Global Change Program.

Edited by: R. Sander

\section{References}

Allan, B. J., Plane, J. M. C., and McFiggans, G.: Observations of OIO in the remote marine boundary layer, Geophys. Res. Lett., 28, 1945-1948, 2001.

Anttila, T., Kerminen, V.-M., Kulmala, M., Laaksonen, A., and O'Dowd, C. D.: Modelling the formation of organic particles in the atmosphere, Atmos. Chem. Phys., 4, 1071-1083, 2004, SRef-ID: 1680-7324/acp/2004-4-1071.

Ashworth, S. H., Allan, B. J., and Plane, J. M. C.: High resolution spectroscopy of the OIO radical: Implications for the ozonedepletion potential of iodine in the marine boundary layer, Geophys. Res. Lett., 29, 1456, doi:10.1029/2001GL013851, 2002.

Atkinson, R., Baulch, D. L., Cox, R. A., Crowley, J. N., Hampson, R. F., Hynes, R. G., Jenkin, M. E., Rossi, M. J., and Troe, J.: Evaluated Kinetic and Photochemical Data for Atmospheric Chemistry: Volume I - gas phase reactions of $\mathrm{O}_{\mathrm{x}}, \mathrm{HO}_{\mathrm{x}}, \mathrm{NO}_{\mathrm{x}}$ and $\mathrm{SO}_{\mathrm{x}}$ species, Atmos. Chem. Phys., 4, 1461-1738, 2004, SRef-ID: 1680-7324/acp/2004-4-1461.

Bloss, W. J., Rowley, D. M., Cox, R. A., and Jones, R. L.: Kinetics and products of the IO self-reaction, J. Phys. Chem. A, 105, 7840-7854, 2001.

Burkholder, J. B., Curtius, J., Ravishankara, A. R., and Lovejoy, E. R.: Laboratory studies of the homogeneous nucleation of iodine oxides, Atmos. Chem. Phys., 4, 19-34, 2004,

SRef-ID: 1680-7324/acp/2004-4-19.

Carpenter, L. J., Sturges, W. T., Penkett, S. A., Liss, P. S., Alicke, B., Hebestreit, K., and Platt, U.: Short-lived alkyl iodides and bromides at Mace Head, Ireland: Links to biogenic sources and halogen oxide production, J. Geophys. Res., 104, 1679-1689, 1999.

Carpenter, L. J., Malin, G., Liss, P. S., and Küpper, F. C.: Novel biogenic iodine-containing trihalomethanes and other short-lived halocarbons in the coastal East Atlantic, Global Biogeochem. Cycles, 14, 1191-1204, 2000.

Charlson, R. J., Schwartz, S. E., Hales, J. M., Cess, R. D., Coakley Jr., J. A., Hansen, J. E., and Hoffmann, D. J.: Climate forcing by anthropogenic aerosols, Science, 255, 423-430, 1992.

Coffman, D. J. and Hegg, D. A.: A preliminary study of the effect of ammonia on particle nucleation in the marine boundary layer, J. Geophys. Res., 100, 7147-7160, 1995.

Fuchs, N. A. and Sutugin, A. G.: Highly dispersed aerosols, Ann Arbor Science Publishers, Ann Arbor, London, 1970.

Garland, J. A. and Curtis, H.: Emission of iodine from the sea surface in the presence of ozone, J. Geophys. Res., 86, 3183-3186, 1981. 
Hoffmann, T., O'Dowd, C., and Seinfeld, J. H.: Iodine oxide homogeneous nucleation: An explanation for coastal new particle production, Geophys. Res. Lett., 28, 1949-1952, 2001.

Hoppel, W. A. and Frick, G. M.: Submicron aerosol size distributions measured over the tropical and south Pacific, Atmos. Environ., 24A, 645-659, 1990.

Ingham, T., Cameron, M., and Crowley, J. N.: Photodissociation of IO $(355 \mathrm{~nm})$ and OIO $(532 \mathrm{~nm})$ : Quantum yields for $\mathrm{O}\left({ }^{3} \mathrm{P}\right) / \mathrm{I}$ production, J. Phys. Chem. A, 104, 8001-8010, 2000.

Jaenicke, R.: Aerosol Physics and Chemistry, in Landolt-Börnstein "Zahlenwerte und Funktionen aus Naturwissenschaften und Technik”, V 4b, pp. 391-457, Springer, 1988.

Janson, R., Rosman, K., Karlsson, A., and Hansson, H.-C.: Biogenic emissions and gaseous precursors to forest aerosols, Tellus, 53B, 423-444, 2001.

Jimenez, J. L., Cocker, D. R., Bahreini, R., Zhuang, H., Varutbangkul, V., Flagan, R. C., Seinfeld, J. H., O’Dowd, C., and Hoffmann, T.: New particle formation from photooxidation of diiodomethane $\left(\mathrm{CH}_{2} \mathrm{I}_{2}\right)$, J. Geophys. Res., 108, 4318, doi:10.1029/2002JD002452, 2003.

Kerminen, V.-M. and Kulmala, M.: Analytical formulae connectiong the 'real' and the 'apparent' nucleation rate and the nuclei number concentration for atmospheric nucleation events, J. Aerosol Sci., 33, 609-622, 2002.

Kerminen, V.-M., Anttila, T., Lehtinen, K. E. J., and Kulmala, M.: Parameterization for atmospheric new-particle formation: application to a system involving sulfuric aicd and condensable watersoluble organic vapors, Aerosol Sci. Technol., 38, 1001-1008, 2004.

Kulmala, M., Kerminen, V.-M., Anttila, T., Laaksonen, A., and O'Dowd, C.: Organic aerosol formation via sulphate cluster activation, J. Geophys. Res., 109, D04205, doi:10.1029/2003JD003961, 2004a.

Kulmala, M., Laakso, L., Lehtinen, K. E. J., Riipinen, I., Maso, M. D., Anttila, T., Kerminen, V.-M., Horrak, U., Vana, M., and Tammet, H.: Initial steps of aerosol growth, Atmos. Chem. Phys., 4, 2553-2560, 2004b,

SRef-ID: 1680-7324/acp/2004-4-2553.

Lohmann, U. and Feichter, J.: Global indirect aerosol effects: a review, Atmos. Chem. Phys., 5, 715-737, 2005,

SRef-ID: 1680-7324/acp/2005-5-715.

McFiggans, G., Coe, H., Burgess, R., Allan, J., Cubison, M., Alfarra, M. R., Saunders, R., Saiz-Lopez, A., Plane, J. M. C., Webvill, D., Carpenter, L., Rickard, A. R., and Monks, P. S.: Direct evidence for coastal iodine particles from Laminaria macroalgae - linkage to emissions of molecular iodine, Atmos. Chem. Phys., 4, 701-713, 2004,

\section{SRef-ID: 1680-7324/acp/2004-4-701.}

Monahan, E. C., Spiel, D. E., and Davidson, K. L.: A model of marine aerosol generation via whitecaps and wave disruption, in: Oceanic Whitecaps, edited by: Monahan, E. C. and Niocaill, G. M., pp. 167-174, D. Reidel, Norwell, Mass, 1986.

Napari, I., Noppel, M., Vehkamäki, H., and Kulmala, M.: Parametrization of ternary nucleation rates for $\mathrm{H}_{2} \mathrm{SO}_{4}-\mathrm{NH}_{3}-\mathrm{H}_{2} \mathrm{O}$ vapors, J. Geophys. Res., 107, 4381, doi:10.1029/2002JD002132, 2002.

O’Dowd, C., McFiggans, G., Creasey, D. J., Pirjola, L., Hoell, C., Smith, M. H., Allan, B. J., Plane, J. M. C., Heard, D. E., Lee, J. D., Pilling, M. J., and Kulmala, M.: On the photochemical production of new particles in the coastal boundary layer, Geophys. Res. Lett., 26, 1707-1710, 1999.

O'Dowd, C. D., Geever, M., Hill, M. K., Smith, M. H., and Jennings, S. G.: New particle formation: Nucleation rates and spatial scales in the clean marine coastal environment, Geophys. Res. Lett., 25, 1661-1664, 1998.

O’Dowd, C. D., Hämeri, K., Mäkelä, J. M., Pirjola, L., Kulmala, M., Jennings, S. G., Berresheim, H., Hansson, H.-C., de Leeuw, G., Kunz, G. J., Allen, A. G., Hewitt, C. N., Jackson, A., Viisanen, Y., and Hoffmann, T.: A dedicated study of new particle formation and fate in the coastal environment (PARFORCE): Overview of objectives and achievements, J. Geophys. Res., 107, 8108, doi:10.1029/2001JD000555, 2002a.

O’Dowd, C. D., Jimenez, J. L., Bahreini, R., Flagan, R. C., Seinfeld, J. H., Hämeri, K., Pirjola, L., Kulmala, M., Jennings, S. G., and Hoffmann, T.: Marine particle formation from biogenic iodine emissions, Nature, 417, 632-636, 2002 b.

Peters, C., Pechtl, S., Stutz, J., Hebestreit, K., Hönninger, G., Heumann, K. G., Schwarz, A., Winterlik, J., and Platt, U.: Reactive and organic halogen species in three different European coastal environments, Atmos. Chem. Phys., 5, 3357-3375, 2005, SRef-ID: 1680-7324/acp/2005-5-3357.

Pirjola, L., O’Dowd, C. D., Brooks, I. M., and Kulmala, M.: Can new particle formation occur in the clean marine boundary layer?, J. Geophys. Res., 105, 26 531-26 546, 2000.

Pirjola, L., O'Dowd, C., and Kulmala, M.: A model prediction of the yield of cloud condensation nuclei from coastal nucleation events, J. Geophys. Res., 107(D19), 8098, doi:10.1029/2000JD000213, 2002.

Pruppacher, H. R. and Klett, J. D.: Microphysics of Clouds and Precipitation, Kluwer Academic Pub., Dordrecht/Boston/London, 1997.

Pundt, I., Mettendorf, K.-U., Laepple, T., Knab, V., Xie, P., Lösch, J., von Friedeburg, C., Platt, U., and Wagner, T.: Measurements of trace gas distributions using Long-path Tomography during the motorway campaign BAB II: Experimental setup and results for $\mathrm{NO}_{2}$, Atmos. Environ., 39, 967-975, 2005.

Richter, U. and Wallace, D. W. R.: Production of methyl iodide in the tropical Atlantic Ocean, Geophys. Res. Lett., 31, L23S03, doi:10.1029/2004GL020779, 2004.

Saiz-Lopez, A. and Plane, J. M. C.: Novel iodine chemistry in the marine boundary layer, Geophys. Res. Lett., 31, L04112, doi:10.1029/2003GL019215, 2004.

Saiz-Lopez, A., Plane, J. M. C., McFiggans, G., Williams, P. I., Ball, S. M., Bitter, M., Jones, R. L., Hongwei, C., and Hoffmann, T.: Modelling molecular iodine emissions in a coastal marine environment: The link to new particle formation, Atmos. Chem. Phys. Discuss., 5, 5405-5439, 2005,

SRef-ID: 1680-7375/acpd/2005-5-5405.

Saunders, R. W. and Plane, J. M. C.: Formation pathways and composition of iodine oxide ultrafine particles, Environ. Chem., 2, 299-303, 2005.

THALOZ: Final report of the EU project THALOZ: Tropospheric Halogens - effect on ozone, coordinated by: Cox, R. A., University of Cambridge, UK, 2005.

Turco, R. P., Zhao, J.-X., and Yu, F.: A new source of tropospheric aerosols: Ion-ion recombination, Geophys. Res. Lett., 25, 635638, 1998. 
Vogt, R., Sander, R., von Glasow, R., and Crutzen, P.: Iodine chemistry and its role in halogen activation and ozone loss in the marine boundary layer: A model study, J. Atmos. Chem., 32, 375$395,1999$.

von Glasow, R., Sander, R., Bott, A., and Crutzen, P. J.: Modeling halogen chemistry in the marine boundary layer. 1 . Cloud-free MBL, J. Geophys. Res., 107, 4341, doi:10.1029/2001JD000942, 2002a. von Glasow, R., Sander, R., Bott, A., and Crutzen, P. J.: Modeling halogen chemistry in the marine boundary layer. 2. Interactions with sulfur and cloud-covered MBL, J. Geophys. Res., 107, 4323, doi:10.1029/2001JD000943, 2002b. 